\title{
The Remarkable Metrological History of Radiocarbon Dating [II]
}

\section{Lloyd A. Currie}

National Institute of Standards and Technology,

Gaithersburg, MD 20899-8370

U.S.A.

1loyd.currie@nist.gov
This article traces the metrological history of radiocarbon, from the initial breakthrough devised by Libby, to minor (evolutionary) and major (revolutionary) advances that have brought ${ }^{14} \mathrm{C}$ measurement from a crude, bulk [ $8 \mathrm{~g}$ carbon] dating tool, to a refined probe for dating tiny amounts of precious artifacts, and for "molecular dating" at the $10 \mu \mathrm{g}$ to $100 \mu \mathrm{g}$ level. The metrological advances led to opportunities and surprises, such as the non-monotonic dendrochronological calibration curve and the "bomb effect," that gave rise to new multidisciplinary areas of application, ranging from archaeology and anthropology to cosmic ray physics to oceanography to apportionment of anthropogenic pollutants to the reconstruction of environmental history.

Beyond the specific topic of natural ${ }^{14} \mathrm{C}$, it is hoped that this account may serve as a metaphor for young scientists, illustrating that just when a scientific discipline may appear to be approaching maturity, unanti- cipated metrological advances in their own chosen fields, and unanticipated anthropogenic or natural chemical events in the environment, can spawn new areas of research having exciting theoretical and practical implications.

Key words: accelerator mass spectrometry; apportionment of fossil and biomass carbon; "bomb" ${ }^{14} \mathrm{C}$ as a global tracer; dual isotopic authentication; metrological history; molecular dating; radiocarbon dating; the Turin Shroud; SRM 1649a.

Accepted: February 11, 2004

Available online: http://www.nist.gov/jres

\section{Contents}

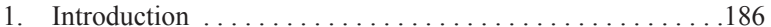

2. The Birth of Radiocarbon Dating ....................186

2.1 Standards and Validation . . . . . . . . . . . . . . . . . . 189

3. Natural Variations . . . . . . . . . . . . . . . . . . . . . 190

4. The Bomb .............................. 192

4.1 Excess ${ }^{14} \mathrm{C}$ as a Global Geochemical Tracer . . . . . . . 193

4.2 The Second (Geochemical) Decay Curve

of ${ }^{14} \mathrm{C}$ : Isotopic-Temporal Authentication .........193

5. Anthropogenic Variations; "Trees Pollute" .............. 195

5.1 Fossil-Biomass Carbon Source Apportionment . . . . . . 196

6. Accelerator Mass Spectrometry .................... 199
6.1 The Invention . . . . . . . . . . . . . . . . . . . . . . . . . 199

6.2 The Shroud of Turin ......................200

7. Emergence of $\mu$-Molar ${ }^{14} \mathrm{C}$ Metrology . . . . . . . . . 204

7.1 Long-Range Transport of Fossil

and Biomass Aerosol ..................205

7.2 Isotopic Speciation in Ancient Bones

and Contemporary Particles ..............210

7.2.1 Urban Dust (SRM 1649a); a Unique

Isotopic-Molecular Reference Material . . . .211

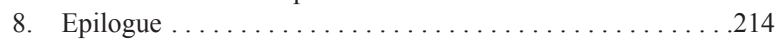

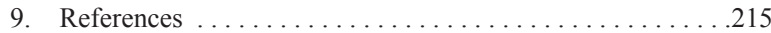




\section{Introduction}

This article is about metrology, the science of measurement. More specifically, it examines the metrological revolutions, or at least evolutionary milestones that have marked the history of radiocarbon dating, since its inception some 50 years ago, to the present. The series of largely or even totally unanticipated developments in the metrology of natural ${ }^{14} \mathrm{C}$ is detailed in the several sections of this article, together with examples of the consequent emergence of new and fundamental applications in a broad range of disciplines in the physical, social, and biological sciences.

The possibility of radiocarbon dating would not have existed, had not ${ }^{14} \mathrm{C}$ had the "wrong" half-life — a fact that delayed its discovery [1]. Following the discovery of this 5730 year (half-life) radionuclide in laboratory experiments by Ruben and Kamen, it became clear to W. F. Libby that ${ }^{14} \mathrm{C}$ should exist in nature, and that it could serve as a quantitative means for dating artifacts and events marking the history of civilization. The search for natural radiocarbon was itself a metrological challenge, for the level in the living biosphere [ca. $230 \mathrm{~Bq} / \mathrm{kg}$ ] lay far beyond the then current state of the measurement art. The following section of this article reviews the underlying concepts and ingenious experimental approaches devised by Libby and his students that led to the establishment and validation of the "absolute" radiocarbon technique.

That was but the beginning, however. Subsequent metrological and scientific advances have included: a major improvement in ${ }^{14} \mathrm{C}$ decay counting precision leading to the discovery of natural ${ }^{14} \mathrm{C}$ variations; the global tracer experiment following the "pulse" of excess ${ }^{14} \mathrm{C}$ from atmospheric nuclear testing; the growing importance of quantifying sources of biomass and fossil carbonaceous contaminants in the environment; the revolutionary change from decay counting to atom counting (AMS: accelerator mass spectrometry) plus its famous application to artifact dating; and the demand for and possibility of ${ }^{14} \mathrm{C}$ speciation (molecular dating) of carbonaceous substances in reference materials, historical artifacts, and in the natural environment.

\section{The Birth of Radiocarbon Dating}

The year before last marked the 50th anniversary of the first edition of Willard F. Libby's monograph, Radiocarbon Dating - published in 1952 [2]. Eight years later Libby was awarded the Nobel Prize in Chemistry. In a very special sense that small volume
(111 pages of text) captured the essence of the path to discovery: from the initial stimulus, to both conceptual and quantitative scientific hypotheses, to experimental validation, and finally, to the demonstration of highly significant applications. The significance of Libby's discovery, from the perspective of the Nobel Committee, is indicated in Fig. 1, which includes also a portrait of Libby in the year his monograph was published [3]. ${ }^{1}$ The statement of the Nobel Committee represents an unusual degree of foresight, in light of unsuspected scientific and metrological revolutions that would take place in ensuing years.

Like many of the major advances in science, Radiocarbon Dating was born of Scientific Curiosity. As noted by Libby in his Nobel Lecture, "it had its origin in a study of the possible effects that cosmic rays might have on the earth and on the earth's atmosphere" [4]. Through intensive study of the cosmic ray and nuclear physics literature, Libby made an important series of deductions, leading to a quantitative prediction of the natural ${ }^{14} \mathrm{C}$ concentration in the living biosphere. As reviewed in chapter I of Libby's monograph, and in the Nobel Lecture, the deductive steps included: (1) Serge Korff's discovery that cosmic rays generate on average about 2 secondary neutrons per $\mathrm{cm}^{2}$ of the earth's surface per second; (2) the inference that the large majority of the neutrons undergo thermalization and reaction with atmospheric nitrogen to form ${ }^{14} \mathrm{C}$ via the nuclear reaction ${ }^{14} \mathrm{~N}(\mathrm{n}, \mathrm{p}){ }^{14} \mathrm{C}$; (3) the proposition that the ${ }^{14} \mathrm{C}$ atoms quickly oxidize to ${ }^{14} \mathrm{CO}_{2}$, and that this mixes with the total exchangeable reservoir of carbon in a period short compared to the ca. 8000 year mean life of ${ }^{14} \mathrm{C}$. Based on the observed production rate of neutrons from cosmic rays (ca. $2 \mathrm{~cm}^{-2} \mathrm{~s}^{-1}$ ), their near quantitative transformation to ${ }^{14} \mathrm{C}$, and an estimate of the global carbon exchangeable reservoir $\left(8.5 \mathrm{~g} / \mathrm{cm}^{2}\right)$, Libby estimated that the steady state radioactivity concentration of exchangeable ${ }^{14} \mathrm{C}$ would be approximately $[(2 \times 60) / 8.5]$ or about 14 disintegrations per minute (dpm) per gram carbon (ca. $230 \mathrm{mBq} \mathrm{g}^{-1}$ ). Once living matter is cut off from this steady state, exponential nuclear decay will dominate, and "absolute dating" will follow using the observed half-life of ${ }^{14} \mathrm{C}$ (5568 years). ${ }^{2}$

\footnotetext{
${ }^{1}$ Figure 1 shows Libby as the author first met him, shortly after the latter entered the University of Chicago as a graduate student in chemistry.

${ }^{2}$ Production rate and reservoir parameters are taken from the Nobel lecture [4]; these values differ somewhat from those used by Libby in [5] and in the first edition of his book [2]. The half-life (5568 a) is the "Libby half-life" which by convention is used to calculate "radiocarbon ages;" the current accepted value for the physical half-life is $(5730 \pm 40)$ a $[5 \mathrm{a}]$.
} 


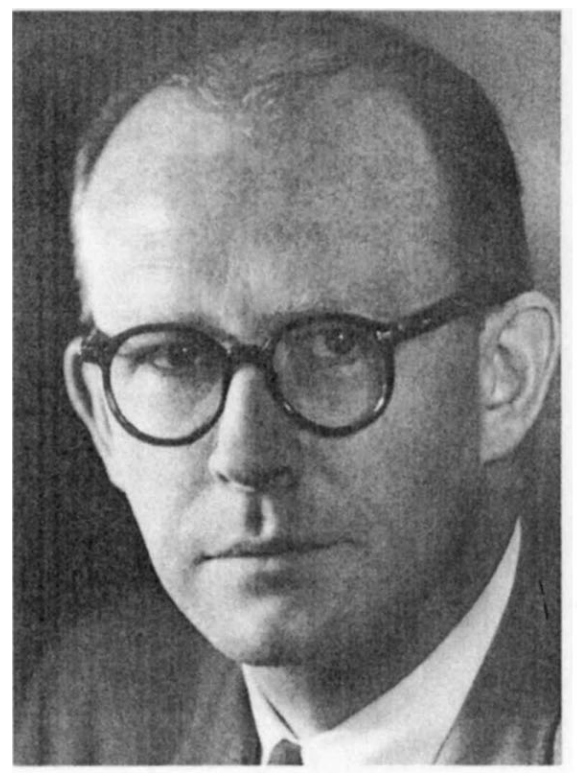

\section{"Seldom has a single discovery in chemistry had such an impact on the thinking in so many fields of human endeavor."}

\section{-Nobel Committee (1960)}

Fig. 1. Portrait of W. F. Libby, about the time of publication of the first edition of his monograph, Radiocarbon Dating (1952), and statement of the Nobel Committee (1960) [3].

Two critical assumptions are needed for absolute ${ }^{14} \mathrm{C}$ dating: constancy of both the cosmic ray intensity and size of the exchangeable reservoir on average for many thousands of years. A graphical summary of the above points is given in Fig. 2.

Libby first postulated the existence of natural ${ }^{14} \mathrm{C}$ in 1946 , at a level of 0.2 to $2 \mathrm{~Bq} / \mathrm{mol}$ carbon $(1 \mathrm{dpm} / \mathrm{g}$ to $10 \mathrm{dpm} / \mathrm{g}$ ) [5]. His first experimental task was to demonstrate this presence of "natural" ${ }^{14} \mathrm{C}$ in living matter. The problem was that, even at $10 \mathrm{dpm} / \mathrm{g}$, the ${ }^{14} \mathrm{C}$ would be unmeasurable! The plan was to search for natural ${ }^{14} \mathrm{C}$ in bio-methane, but the background of his well-shielded 1.9 L Geiger counter (342 counts per minute) exceeded the expected signal by a factor of 400. Libby and coworkers did succeed in demonstrating the presence of ${ }^{14} \mathrm{C}$ in living matter, however. For an account of their creative approach to the problem, see their one page article in Science, "Radiocarbon from Cosmic Radiation" [6]. ${ }^{3}$

Having detected ${ }^{14} \mathrm{C}$ in the living biosphere, Libby and his colleagues had to develop a measurement technique that was both quantitative and practical. The

\footnotetext{
${ }^{3}$ To fully appreciate the nature of the experimental impediments and flashes of insight along the path to discovery, students are encouraged to study the original scientific literature, as given here, rather than restricting attention to subsequent summaries in textbooks.
}

thermal diffusion enrichment technique [6] was not: it demanded very large samples and thousands of (1946) US dollars "to measure the age of a single mummy" [4]. Development of an acceptable technique was formidable, as outlined in Table 1. A substantial increase in signal was achieved by converting the sample to solid carbon, which coated the inner wall of a specially designed "screen wall counter;" but the background/signal ratio (16:1) still eliminated the possibility of meaningful measurements. At this point, Libby had an inspiration, from the analysis of the nature of the background radiation [4]. He concluded that it was primarily due to secondary, ionizing cosmic radiation having great penetrating power-negative mu mesons $\left(\mu^{-}\right)$. By surrounding the sample counter with cosmic ray guard counters operating in an anti-coincidence mode, most of the $\mu^{-}$counts could be eliminated, resulting in a further background reduction by a factor of twenty, to approximately 5 counts per minute (cpm). The final background to signal ratio of 0.8 for living carbon, made possible the measurement of natural (biospheric) ${ }^{14} \mathrm{C}$ with a precision under $2 \%$ (Poisson relative standard deviation) with a total (sample, background) counting time of just $2 \mathrm{~d}$ ([2], Chap. V). Fig. 3 shows the low-level counting apparatus devised by Libby, with which the seminal ${ }^{14} \mathrm{C}$ dating measurements 


\section{PRODUCTION OF ${ }^{14} \mathrm{C}$}

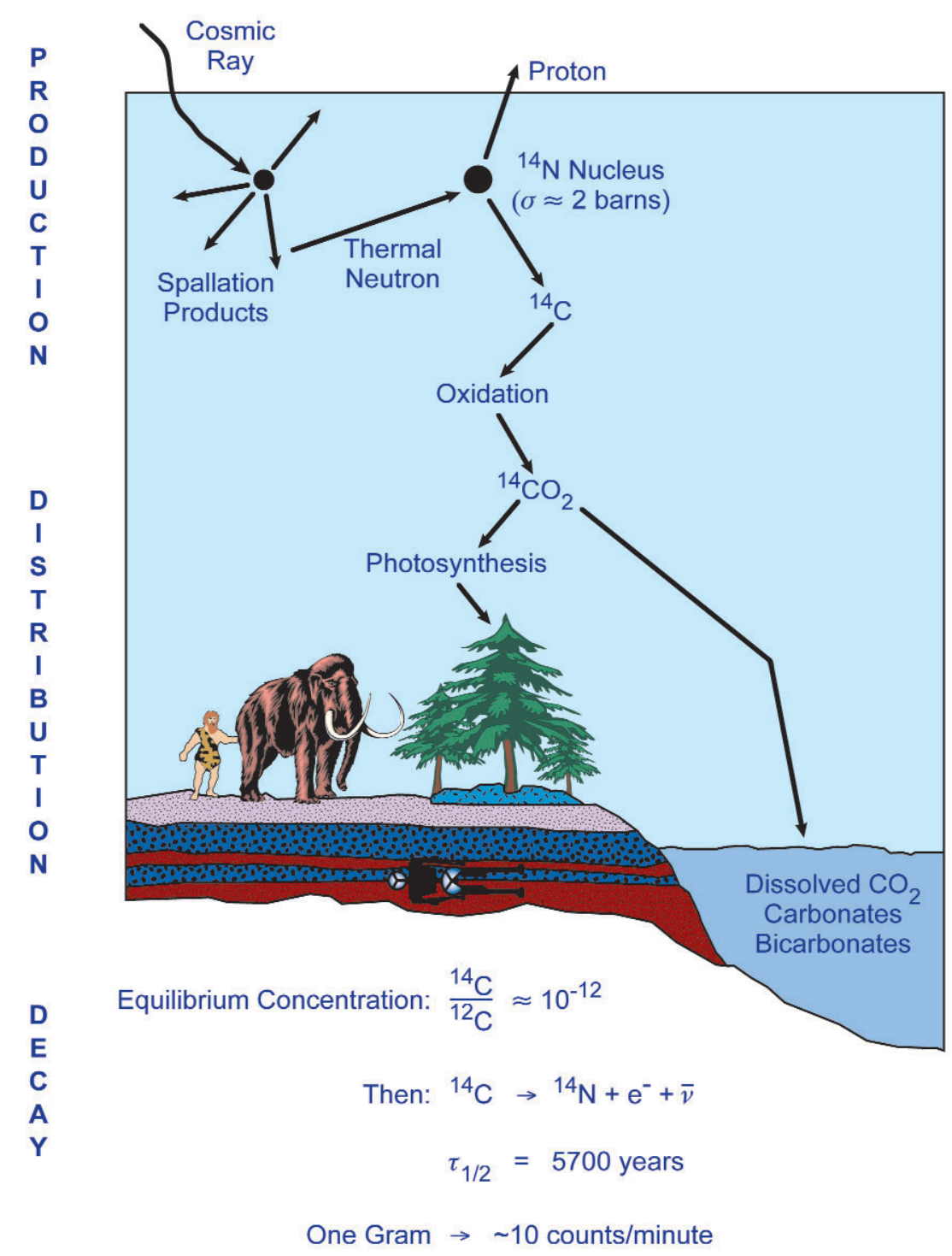

Fig. 2. Graphical representation of the production, distribution, and decay of natural ${ }^{14} \mathrm{C}$ (courtesy of D. J. Donahue).(Parameter values are approximate.)

were made. The ${ }^{14} \mathrm{C}$ screen wall counter is visible through the open, 8 inch thick cantilevered steel doors having a wedge-like closure. The steel "tomb" reduces the background by about a factor of five. The bundle of anticoincidence cosmic ray guard counters, seen surrounding the central counter in the figure, eliminates some $95 \%$ of the residual background from the penetrating $\mu^{-}$radiation, through electronic cancellation.
Table 1. Libby's Measurement Challenge

\begin{tabular}{l}
\hline - Cosmic ray neutron intensity: $2 \mathrm{n} \mathrm{cm}^{-2} \mathrm{~s}^{-1}$ \\
- Exchangeable carbon reservoir: $8.5 \mathrm{~g} \mathrm{~cm}^{-2}$ \\
- Estimated ${ }^{14} \mathrm{C}$ activity: $14 \mathrm{dpm} \mathrm{g}^{-1}\left(0.23 \mathrm{~Bq} \mathrm{~g}{ }^{-1}\right)$ \\
- Sample size (detector efficiency): $8 \mathrm{~g} \mathrm{carbon}^{-}(5.5 \%)$ \\
- Estimated modern carbon rate $6.2 \mathrm{cpm}\left(\mathrm{min}^{-1}\right)$ \\
- Background rate: $500 \mathrm{cpm}$ (unshielded), $100 \mathrm{cpm}(20 \mathrm{~cm} \mathrm{Fe})$ \\
Assumptions: \\
Constant production rate \\
Fixed exchangeable $\mathrm{C}$ reservoir (uniform distribution)
\end{tabular}




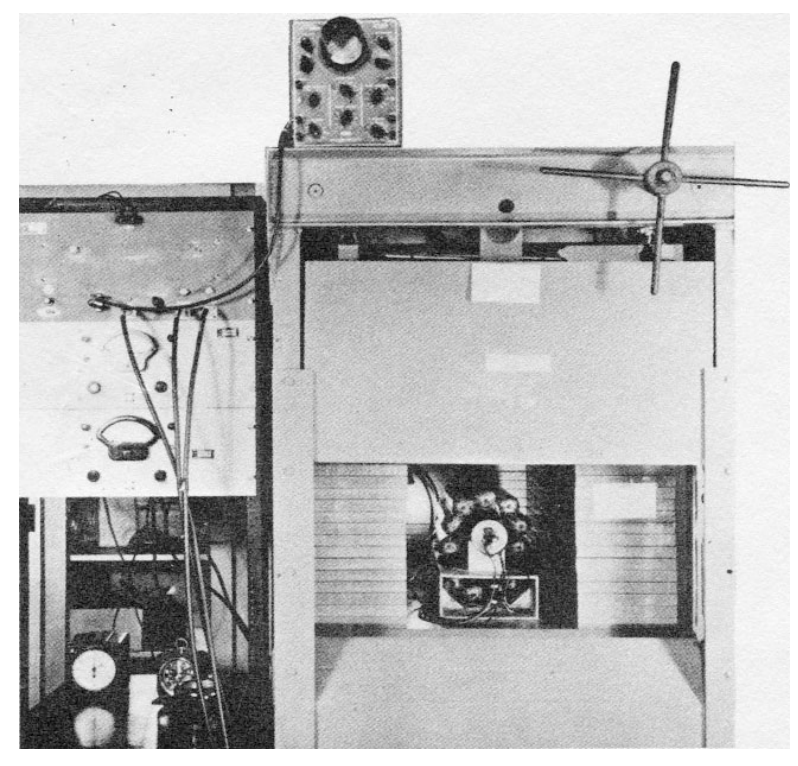

Fig. 3. Low-level anticoincidence counting apparatus devised by Libby for the original ${ }^{14} \mathrm{C}$ measurements that led to the establishment of the radiocarbon dating technique (Ref. [2], and Radiocarbon Dating (jacket cover) R. Berger and H. Suess, eds., Univ. California Press, Berkeley (1979).)

Perhaps the most valuable metrological lesson from Libby's early work was the extreme importance of formulating a realistic theoretical estimate for the sought-after "signal." Without that as a guideline for designing a measurement process with adequate detection or quantification capabilities, there is essentially no possibility that natural radiocarbon could have been found by chance with the then current radiation instrumentation.

\subsection{Standards and Validation}

Once the measurement of natural ${ }^{14} \mathrm{C}$ became feasible, the immediate task tackled by Libby and his colleagues was to test the validity of the radiocarbon dating model. The first step consisted of determining the zero point of the natural radiocarbon decay curve- - i.e., the radioactivity concentration $\left(\mathrm{dpm}{ }^{14} \mathrm{C}\right.$ per gram $\left.\mathrm{C}\right)$ in living matter, and to test for significant geographic variation. This was a major component of the $\mathrm{PhD}$ thesis of E. C. Anderson [7]; the result $\left(R_{\mathrm{o}}\right)$ was $(15.3 \pm 0.5) \mathrm{dpm} / \mathrm{g}$ $[255 \mathrm{~Bq} / \mathrm{kg}]$ with no significant deviation from the hypothesis of a uniform global distribution. ${ }^{4}$ The next

\footnotetext{
${ }^{4}$ The neutron intensity in the atmosphere, and hence the ${ }^{14} \mathrm{C}$ production profile, has major variations vertically (because of cosmic ray absorption with atmospheric depth) and latitudinally (because of geomagnetic shielding)-See Figs. 2 and 3 in Ref. [2]. Because ${ }^{14} \mathrm{C}$ has such a long mean life $(\approx 8000$ a), however, it was expected that any residual gradients in the global exchange reservoir would be undetectable, given the $3 \%$ to $5 \%$ uncertainties of Libby's original measurements (Ref. [2], Chap. I).
}

step was to measure the ${ }^{14} \mathrm{C}$ concentrations in selected historical artifacts of known age, and compare them to the "absolute" ${ }^{14} \mathrm{C}$ age. The latter was accomplished by comparing the artifact ${ }^{14} \mathrm{C}$ concentration $(\mathrm{dpm} / \mathrm{g} \mathrm{C})$ to that of the living biosphere. The absolute age derives from the inversion of first order nuclear decay relation, using $15.3 \mathrm{dpm} / \mathrm{g}$ and $5568 \mathrm{a}$ as the parameters of the "absolute" natural ${ }^{14} \mathrm{C}$ decay curve.

The famous result, utilizing known age tree rings and independently-dated Egyptian artifacts, is shown in Chapter I of Libby's 1952 monograph and Fig. 4 in this article. Although the relative measurement uncertainties are moderately large (ca. $1 \%$ to $5 \%$ ), the data provide a striking validation for the radiocarbon dating method over a period of nearly 5000 years. Note that the curve shown is not fit to the data! Rather, it represents the absolute, two-parameter nuclear decay function. (See [8] for detailed information on the validation samples selected.)

This initial absolute dating function served to establish the method, but it indicated the need for a universal radiocarbon dating standard, since the reference value for the intercept (here $15.3 \mathrm{dpm} / \mathrm{g}$ ) would vary

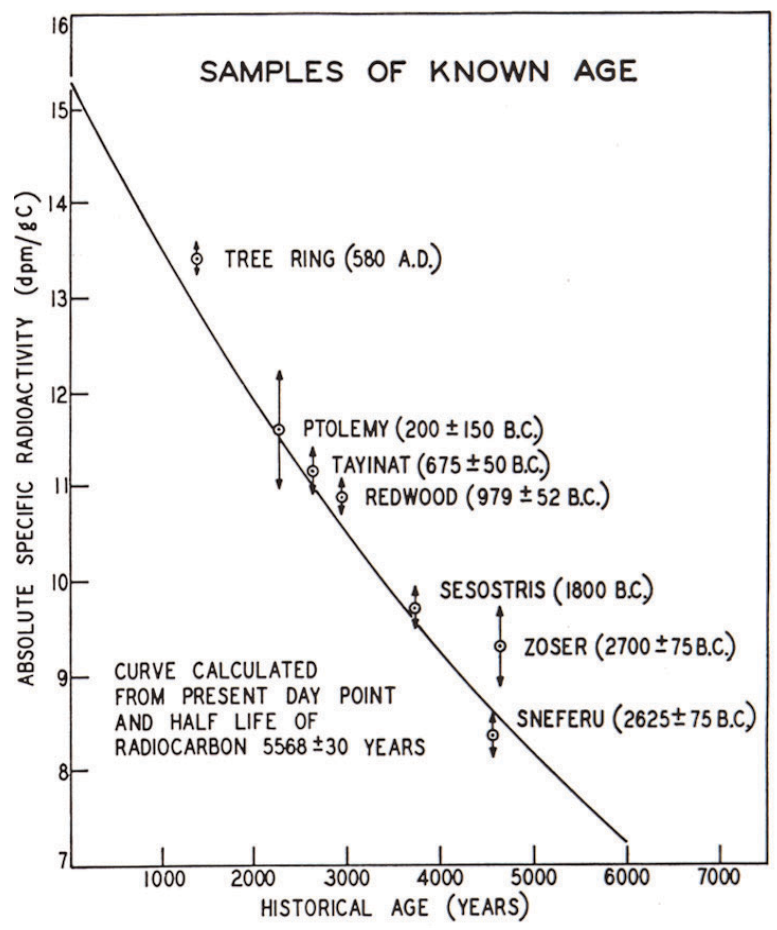

Fig. 4. Radiocarbon dating validation curve (1952): the "curve of knowns" that first demonstrated that absolute radiocarbon dating "worked." The validation points represent tree rings and historical artifacts of known age. The exponential function is not fit to the data, but derived from the independently measured half-life and the ${ }^{14} \mathrm{C}$ content of living matter ([2], Fig. 1). 
among laboratories, if they each made their own standards. The problem was tackled by the international radiocarbon community in the late 1950 s, in cooperation with the U.S. National Bureau of Standards. A large quantity of contemporary oxalic acid di-hydrate was prepared as NBS Standard Reference Material (SRM) 4990B. Its ${ }^{14} \mathrm{C}$ concentration was ca. $5 \%$ above what was believed to be the natural level, so the standard for radiocarbon dating was defined as 0.95 times the ${ }^{14} \mathrm{C}$ concentration of this material, adjusted to a ${ }^{13} \mathrm{C}$ reference value of -19 per mil (PDB). This value is defined as "modern carbon" referenced to AD 1950. Radiocarbon measurements are compared to this modern carbon value, and expressed as "fraction of modern" $\left(f_{\mathrm{M}}\right)$; and "radiocarbon ages" are calculated from $f_{\mathrm{M}}$ using the exponential decay relation and the "Libby half-life" 5568 a. The ages are expressed in years before present (BP) where "present" is defined as AD 1950. A published estimate for the ${ }^{14} \mathrm{C}$ concentration of "modern carbon" is given as $(13.53 \pm 0.07)$ dpm/g [9]. In July 1983, a replacement SRM 4990C was substituted for the nearly exhausted SRM 4990B. It was prepared from oxalic acid derived from the fermentation of French beet molasses from harvests of 1977. A copy of the Certificate Analysis of SRM 4990C, together with pertinent references, may be obtained from the website: http://nist.gov/srm [10]. ${ }^{5}$

Libby's successful development of the science of radiocarbon dating led to the rapid establishment of more than a hundred dating laboratories world-wide, the initiation of a journal supplement that later became the journal Radiocarbon, and the establishment of a continuing series of triennial RADIOCARBON conferences, the first of which took place in Andover, Massachusetts in 1954.

\section{Natural Variations}

Already, by the time the Nobel Prize was awarded, Radiocarbon Dating appeared to be approaching maturity, with a rich future in application as opposed to new fundamental discovery. This all changed, however, when some of the fundamental assumptions proved to be invalid - what might be considered as the "failure of Radiocarbon Dating."

\footnotetext{
${ }^{5}$ Several secondary standards for ${ }^{14} \mathrm{C}$ dating are available through the International Atomic Energy Agency. These materials, designated IAEA $\mathrm{C} 1-\mathrm{C} 8$, consist of wood, cellulose, sucrose, and carbonate; they cover a range of $0.00 \mathrm{pMC}$ to $150.6 \mathrm{pMC}$, and have been subject to an international comparison [11]. Note that pMC (percent modern carbon) refers to $f_{\mathrm{M}}$ expressed as a percentage.
}

This "failure" resulted from basic advances in ${ }^{14} \mathrm{C}$ metrology. New approaches to low-level counting yielded measurement imprecision that ultimately approached $0.2 \%$ (rsd); ${ }^{6}$ and construction of the "radiocarbon dating calibration curve" from meticulously counted annual tree ring segments showed that assumptions of constancy within different geochemical compartments of the exchangeable carbon reservoir, and over time, were invalid. (This is a classic example demonstrating that one cannot prove the "null hypothesis;" the validation curve that established the radiocarbon dating method demonstrated consistency (validity) only within the errors (uncertainties) of the validation measurements.) The failure of the absolute dating model was, in fact, a notable success. The revolutionary discovery of natural radiocarbon variations literally arose out of the "noise" of absolute radiocarbon dating, and it transformed the study of natural ${ }^{14} \mathrm{C}$ into a multidisciplinary science, giving rise to totally new scientific disciplines of ${ }^{14} \mathrm{C}$ solar and geophysics.

At his opening address at the 12th Nobel Symposium on Radiocarbon Variations and Absolute Chronology [12] in Uppsala, Nobelist Kai Siegbahn emphasized that "This subject is [now] interesting to specialists in many different fields, as can be seen from the list of participants, showing archaeologists, chemists, dendrochronologists, geophysicists, varved-clay geologists, and physicists" (Ref. [12], pp. 19f). An early version of the dendrochronological ${ }^{14} \mathrm{C}$ calibration curve, presented by Michael and Ralph at the Symposium, is given in Fig. 5 (Ref. [12], p. 110). ${ }^{7}$ The Bristlecone pine, as shown in the figure, has made a seminal contribution to the science of dendrochronology, and through that, to the study of natural ${ }^{14} \mathrm{C}$ variations. It is considered by some to be the world's "oldest living thing," with a single tree containing annual rings going back 4000 years or more. It is clear from Fig. 5

\footnotetext{
${ }^{6}$ The deciding factor for high precision ${ }^{14} \mathrm{C}$ measurement was the successful development of $\mathrm{CO}_{2}$ gas proportional counting, after several failed attempts. Compared to Libby's solid sample (graphite) technique, the $\mathrm{CO}_{2}$ method resulted in smaller sample sizes and efficiency enhancement by nearly a factor of twenty.

${ }^{7}$ The relatively imprecise dendro-calibration curve in Fig. 5 extends to ca. 5000 BC. Meanwhile, the radiocarbon dating calibration function has undergone considerable refinement: it now comprises an extensive database, and it has become an essential element of all radiocarbon dating. The 1986 Calibration Issue of the journal Radiocarbon [13] has a compilation going back to ca. $8000 \mathrm{BC}$. More recent attempts at extending the record much further back in time have utilized ${ }^{14} \mathrm{C}$ comparisons with other dating methods, notably U/Th disequilibrium dating. By this means, calibration data have been given for periods beyond $20000 \mathrm{BC}$ [14].
} 


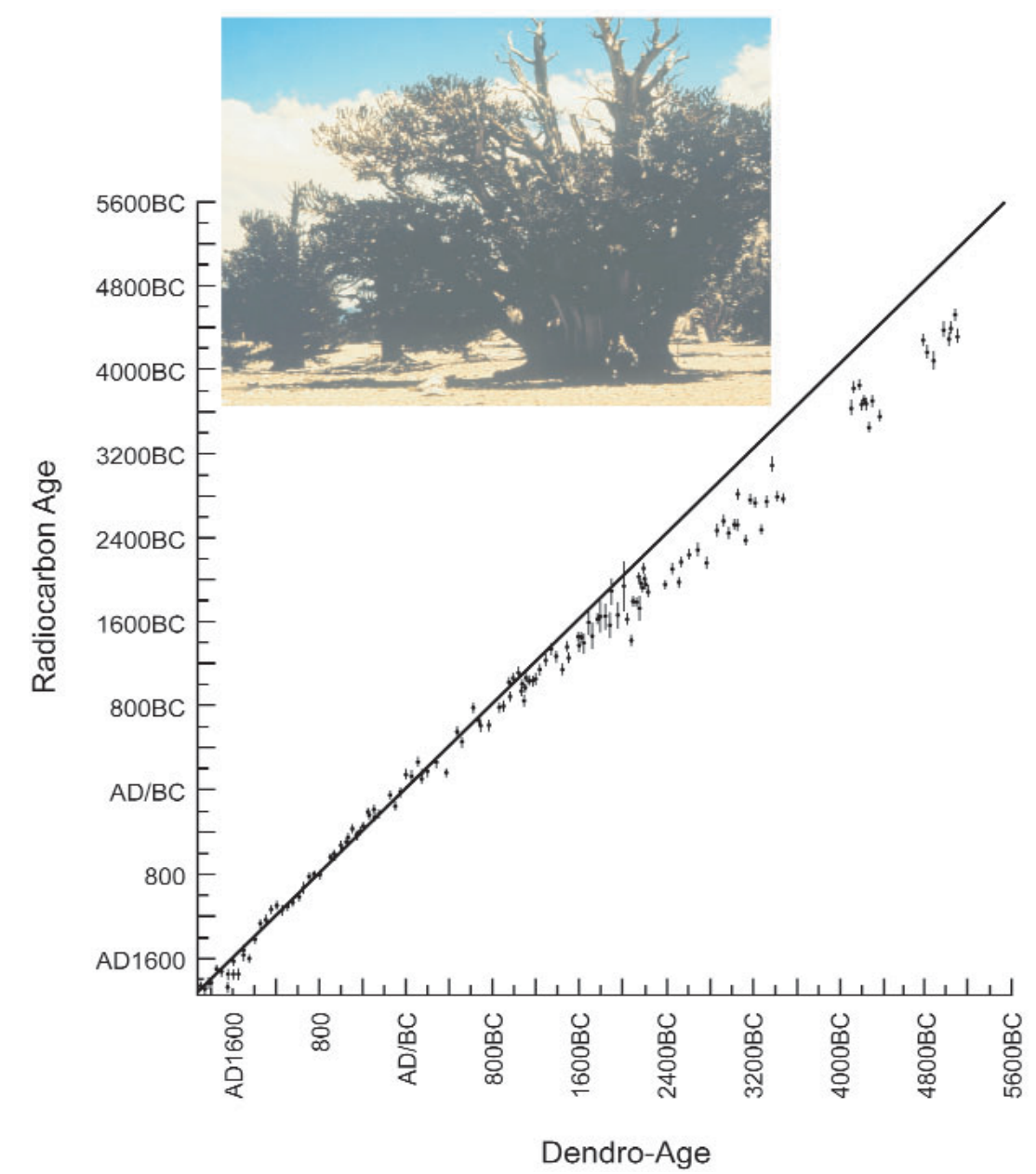

Fig. 5. Radiocarbon Variations, discovered by comparison of high precision radiocarbon "dates" with high (annual) accuracy tree ring dates. The plot, which covers the period from about $5000 \mathrm{BC}$ to the present, represents an early version of the radiocarbon dating calibration curve ([12], p.110). The photo shows the Bristlecone pine, the major source of dendrodates extending back many millennia (Photo is courtesy of D. J. Donahue).

that the dendrochronological age shows a significant departure from the absolute ${ }^{14} \mathrm{C}$ (nuclear) age, beginning about three thousand years ago, and continuing through the end of this series of measurements (ca. $5000 \mathrm{BC}$ ). These newly discovered deviations from the absolute dating model, of course, posed new scientific questions: what are the causes of the deviations, and can we use them to better understand Nature? In fact, the dendro-calibration curve serves dual purposes. For more classic "dating" disciplines, such as archaeology, anthropology, and geology (event dating), it gives an empirical correction function for the simple radiocarbon ages (BP) derived from the first order decay relation. For solar and geophysics and related disciplines, it gives the potential for the quantitative investigation of the causes of the variations.
The Nobel Symposium serves as a rich resource for information about the natural ${ }^{14} \mathrm{C}$ variations. An excellent exposition of the three prime causative factors is given by Hans Suess (Ref. [12], pp. 595-605). These are: "(1) changes in the ${ }^{14} \mathrm{C}$ production rate due to changes in the intensity of the [earth's] geomagnetic field; (2) ... modulation of the cosmic-ray flux by solar activity; (3) changes in the geochemical radiocarbon reservoirs and rates of carbon transfer between them." The major departure (ca. $10 \%$ ) seen in Fig. 5 is considered to be due to the geomagnetic field, corresponding to a factor of two change in its intensity over the past 8000 years [15]. This has given major impetus to the science of archaeomagnetism. The other two factors are considered responsible for the partly periodic fine structure exhibited in the curve, with varying 


\section{RADIOCARBON AND SOLAR ACTIVITY}
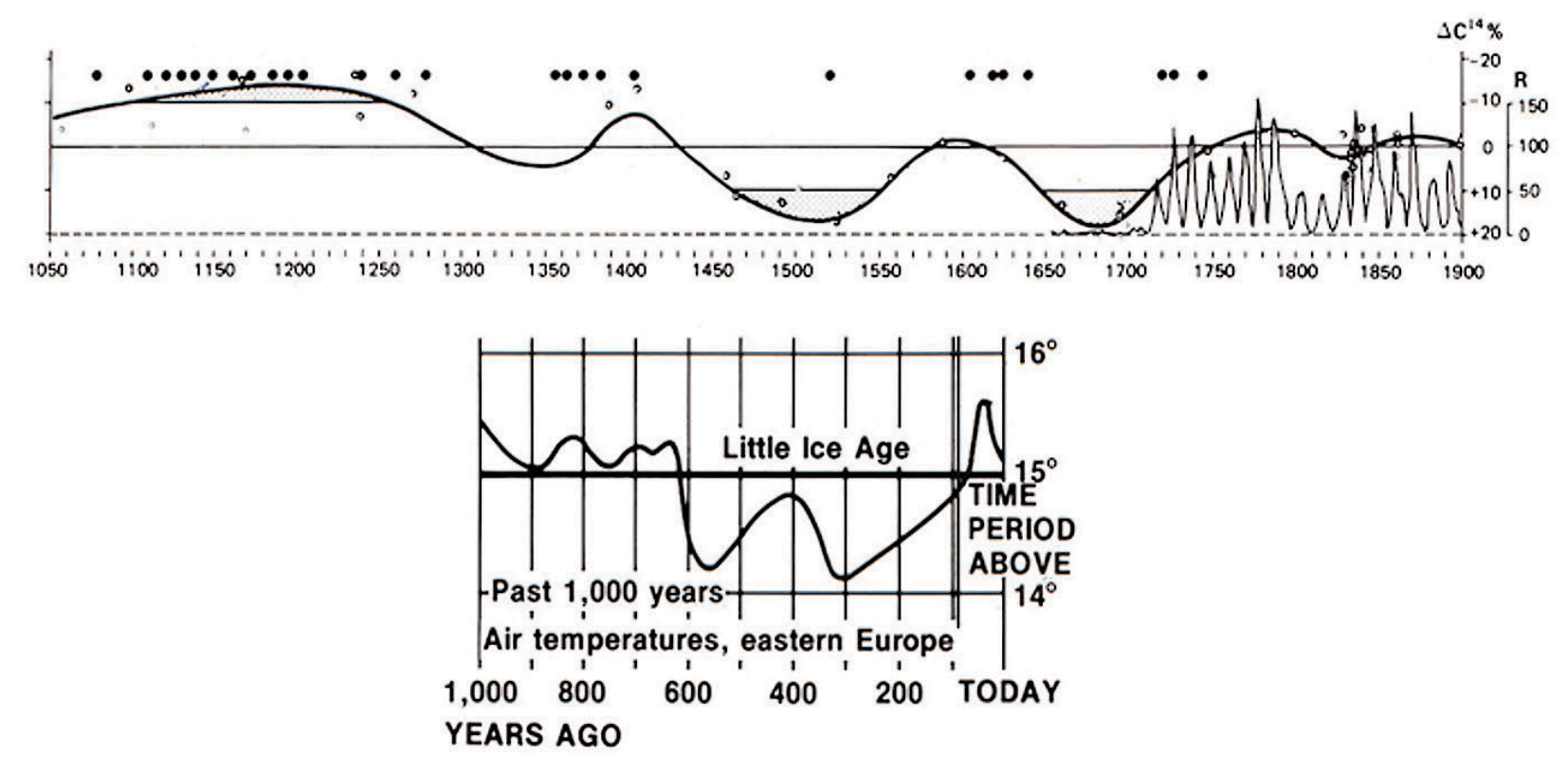

\section{CLIMATE}

Fig. 6. Radiocarbon Variations and Climate: the influence of solar activity (sunspot record) (top) on ${ }^{14} \mathrm{C}$ concentrations (cosmic ray production rates) and climate (Maunder Minimum temperature record) (bottom) $[15,16]$.

amplitudes of about $1 \%$ to $2 \%$. (See Figs. 1, 2 in the Suess article, respectively, for plots of the first order (geomagnetic) and second order (fine structure) deviations from the ideal exponential decay function ("radiocarbon age").)

A fascinating link exists between dendrochronology and radiocarbon age, related to climate. That is, tree rings by their width time series, like ice cores by their ${ }^{18} \mathrm{O}$ time series, give insight into ancient climate [16]. This, in turn, may be linked to the aforementioned ${ }^{14} \mathrm{C}$ variations from changing solar activity and/or variations in geochemical reservoirs. Fig. 6 represents a famous example of the inter-relationships among solar activity (sunspots), natural radiocarbon variations, and climate (Ref. [15], Fig. 5a; Ref. [16], p. 615). The upper part of the figure shows the correlation between the sunspot record (circles, and ca. 11 year cycles) and the ${ }^{14} \mathrm{C}$ variations. The period of low solar activity, and correspondingly increased ${ }^{14} \mathrm{C}$ activity, peaking at about $1500 \mathrm{AD}$ and $1700 \mathrm{AD}$ is striking. The lower part of the figure suggests a strong link to global climate, represented here by the "little ice age."

\section{The Bomb}

Atmospheric nuclear testing had an unintended but profound impact on ${ }^{14} \mathrm{C}$ geoscience. It approximately doubled the ${ }^{14} \mathrm{C}$ concentration in atmospheric $\mathrm{CO}_{2}$, and consequently in living matter, by the mid-1960s. This came about because neutrons released from nuclear fission (or fusion) react with atmospheric nitrogen by exactly the same reaction, ${ }^{14} \mathrm{~N}(\mathrm{n}, \mathrm{p}){ }^{14} \mathrm{C}$, as the secondary neutrons from cosmic rays. The "bomb pulse" of excess ${ }^{14} \mathrm{C}$ was recorded in all parts of the living biosphere, from vintage wine [17] to contemporary tree rings [18]. It was characterized by a sharp injection of ${ }^{14} \mathrm{C}$ in the early 1960 s, followed by relatively slow geochemical decay after the limited (atmospheric) nuclear test ban treaty. Totally new and unanticipated opportunities to perform global tracer experiments resulted from this 


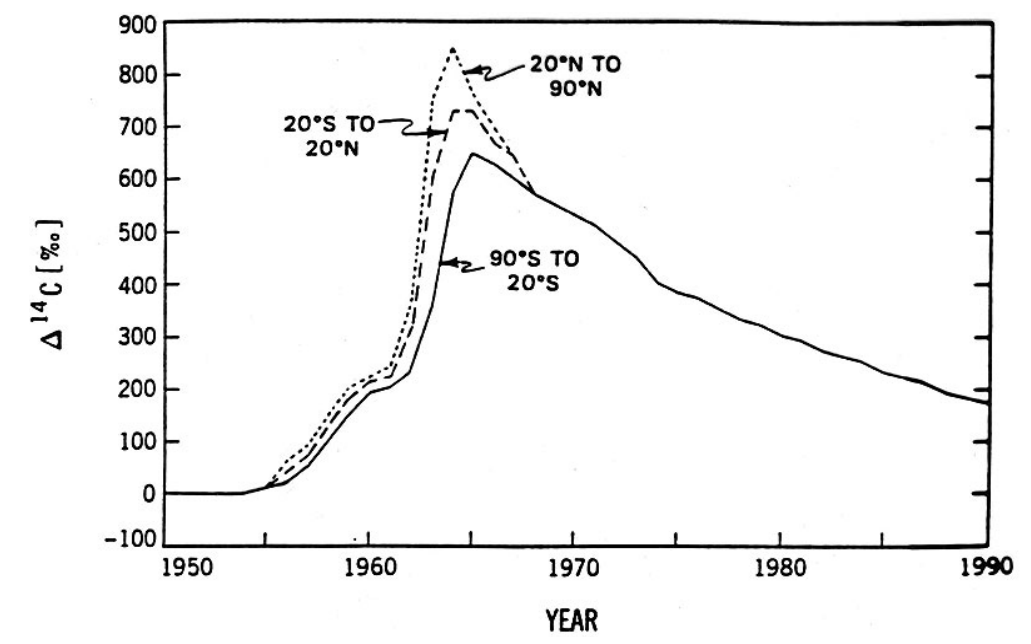

Fig. 7. Input function of excess ("bomb") ${ }^{14} \mathrm{C}$ : a global tracer for carbon cycle dynamics in the atmosphere, biosphere, and oceans [19].

sudden, widespread injection of anthropogenic ${ }^{14} \mathrm{C}$ into the biogeochemical system.

\subsection{Excess ${ }^{14} \mathrm{C}$ as a Global Geochemical Tracer}

An extensive world-wide program of monitoring the excess atmospheric ${ }^{14} \mathrm{CO}_{2}$ began with the onset of nuclear testing and continues today. Results of precise measurements of the input function for excess ${ }^{14} \mathrm{CO}_{2}$ are shown in Fig. 7 (Ref.[19]; Ref. [20], Chap. 31, (I. Levin, et al.)). Use of this known pulse of excess ${ }^{14} \mathrm{C}$ as a tracer has allowed scientists to study exchange and transport processes in the atmosphere, the biosphere, and the oceans on a scale that would otherwise have been nearly impossible. Simple visual examination of Fig. 7 shows, for example, that the excess atmospheric ${ }^{14} \mathrm{C}$ injected in the northern hemisphere gave an attenuated signal in the southern hemisphere, and that there was a lag time of approximately 2 years.

Nowhere has the bomb pulse been more important than in furthering our understanding of the dynamics of the ocean. A comprehensive program (GEOSECS: Geochemical Ocean Section Study) to follow the plume of excess ${ }^{14} \mathrm{C}$ as it diffused in the Atlantic and Pacific oceans was initiated in the 1970s. A small example of the findings is given in Fig. 8, where we find a nearly uniform distribution below the mixed layer, indicating rapid vertical transport in the North Atlantic, in contrast to model predictions $[19,21]$. The scientific impact of this massive tracer study of ocean circulation is striking, considering, for example, the new knowledge it brings regarding the effects of the oceans on pollutant and heat transport and climate [22]. ${ }^{8}$

\subsection{The Second (Geochemical) Decay Curve of ${ }^{14} \mathrm{C}$ : Isotopic-Temporal Authentication}

Geochemical relaxation of the excess atmospheric ${ }^{14} \mathrm{C}$ after about 1970 has resulted in a second (shortlived) "decay curve" for ${ }^{14} \mathrm{C}$ (tail of the input function, Fig. 7). This has made possible a new kind of radiocarbon dating, where modern artifacts and forgeries, food products, forensic biology samples, and industrial bio-feedstocks can be dated with near annual resolution [24]. As a result of the new submilligram measurement capability (Sec. 6), short-term radiocarbon dating is beginning to achieve commercial importance, as exemplified by its application to the dual isotopic $\left({ }^{13} \mathrm{C},{ }^{14} \mathrm{C}\right)$ fingerprinting and time stamping of industrial materials.

A case in point is the Cooperative Research and Development project between the NIST Chemical Science and Technology Laboratory and the DuPont Central Research and Development Laboratory [25].

\footnotetext{
${ }^{8}$ The advent of accelerator mass spectrometry, as discussed in Sec. 6 of this article, has given a major boost to our knowledge of ocean circulation. Information gained through the GEOSECS program has been greatly amplified in the World Ocean Circulation Experiment (WOCE), where requisite sample sizes were reduced from $200 \mathrm{~L}$ of sea water each, to less than $1 \mathrm{~L}$; and the ${ }^{14} \mathrm{C}$ ocean circulation database grew by more than 10000 dates during the 1990s [23].
} 


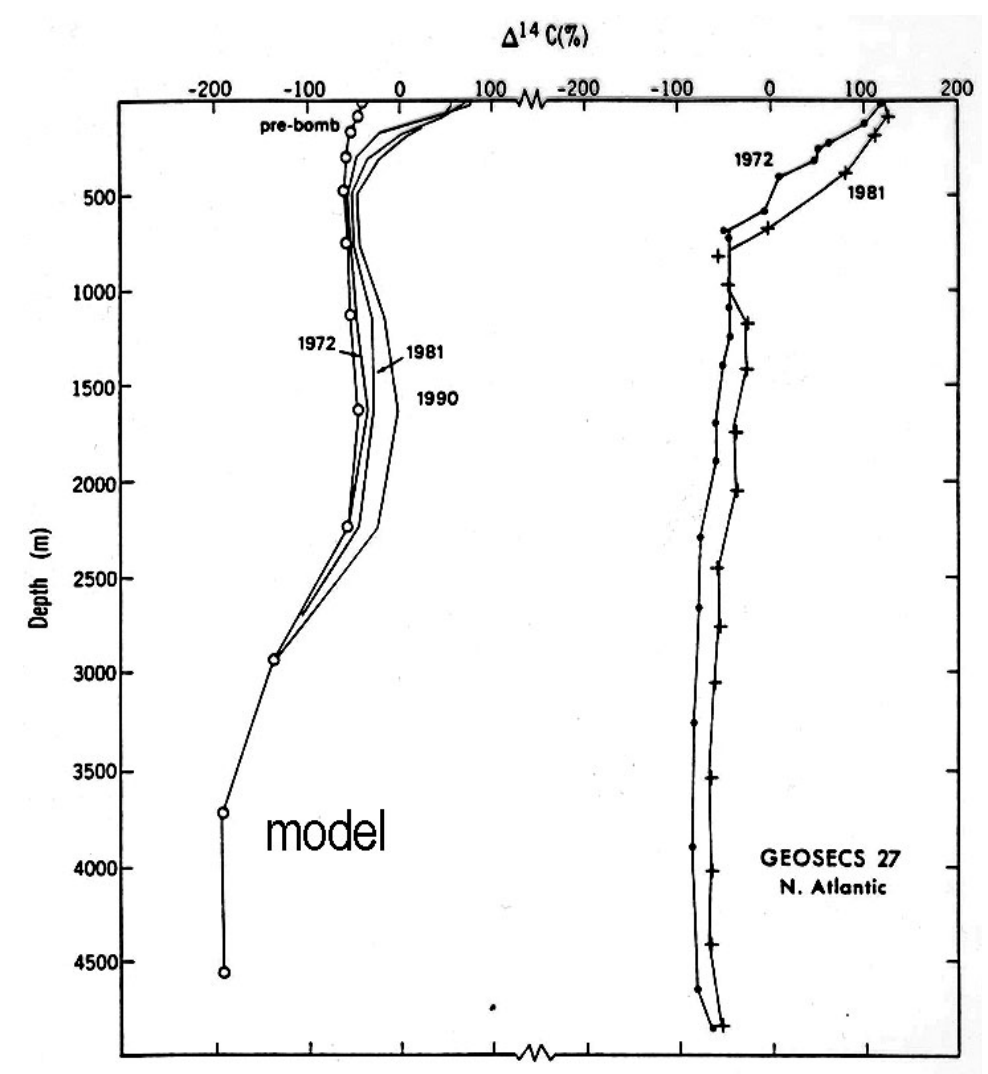

Fig. 8. Excess ${ }^{14} \mathrm{C}$ and ocean circulation (GEOSECS). Model (left) and experimental (right) vertical transects of bomb ${ }^{14} \mathrm{C}$ in the North Atlantic [19].

The goal of the project was to demonstrate the capability to authenticate and date renewable (biosourced) feedstocks, chemical intermediates, and finished industrial products using high accuracy dual isotopic $\left({ }^{13} \mathrm{C}-{ }^{14} \mathrm{C}\right)$ "fingerprinting," traceable to NIST. The specific project, as outlined in Fig. 9, was directed toward the unambiguous identification of the copolymer polypropylene terephthalate (3GT)) produced from the biosourced monomer 1,3-propanediol (3G), which was derived from corn as feedstock. (Terephthalic acid (TPA) served as the complementary monomer.) Isotopic discrimination was essential because it is not possible chemically to distinguish the biosourced $3 \mathrm{G}$ and 3GT from existing industrial materials that are fossil feedstock (petroleum) based. The ability to establish a unique isotopic fingerprint for the DuPont biotechnology materials was critical for the identification of the product as a unique composition of matter, and to track it in commerce. The work represents a frontier of high accuracy, dual isotope metrology, with ${ }^{13} \mathrm{C}$ data $u_{\mathrm{r}}<0.01 \%$ ) serving to discriminate among different photosynthetic cycles, and ${ }^{14} \mathrm{C}$ data $\left(u_{\mathrm{r}}<0.5 \%\right)$ serving both for quantitative fossil-biomass apportionment and for dating the year of growth of the biomass feedstock.

A graphical summary of the results of the project is presented in Fig. 10, which shows the dual isotopic signatures of the copolymer (3GT) and bio-sourced 


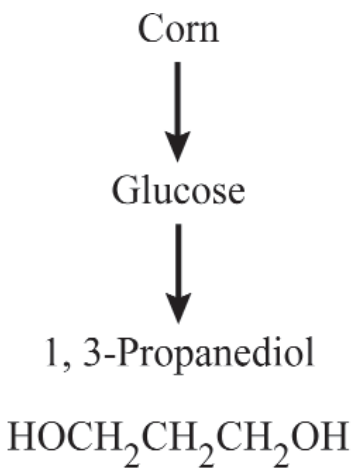

Biomass Carbon

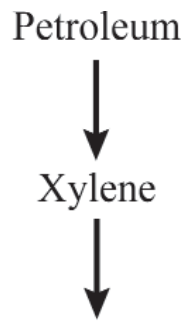

Terephthalic Acid<smiles>O=C(O)c1ccc(C(=O)O)cc1</smiles>

Fossil Carbon

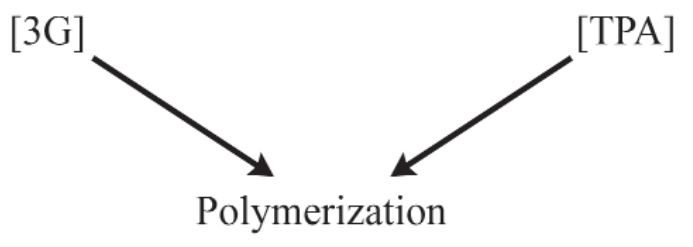<smiles>CC(=O)c1ccc(C(=O)CCC[OH2+])cc1</smiles>

[3GT]

\title{
Polypropylene Terephthalate
}

\begin{abstract}
Fig. 9. Polypropylene Terephthalate: biomass and fossil feedstocks. The 1,3, propanediol monomer is derived from a renewable (biomass) feedstock via laboratory biotechnology: conversion of glucose or cornstarch using a single microorganism. The copolymer has potential large volume demand, and is useful as a fiber, film, particle, and a molded article [25].
\end{abstract}

monomer (3G); as well as values for isotopic reference materials (S1: SRM 4990B [oxalic acid]; S2: IAEA C6 [ANU sucrose]; S3: SRM 1649a [urban dust]), and pre-existing materials $\left(3 \mathrm{G}^{\prime}, 3 \mathrm{G}^{\prime \prime}\right)$. The dashed line joining the copolymer end members (3G, TPA) demonstrates isotopic-stoichiometric mass balance. Rectangular regions in red define the "scope of claims" (authentication regions) for the new isotopic compositions. The blue " $x$ " in the figure represents data for an independent batch of the monomer-sent to NIST "blind" to test the validity of the authentication region for bio-sourced 3G. The results show both that the test was successful and that the separate production batches of the $3 \mathrm{G}$ monomer had unique isotopic signatures. The approximately ten-fold expansion of the isotopic data for two independent batches $(\mathrm{A}, \mathrm{B})$ of corn-glucose (bottom right) demonstrates the dual isotopic discrimination capability of the technique. In fact, using the short term "decay" curve of ${ }^{14} \mathrm{C}$ (Fig. 11), it was possible to date the two batches to the nearest year of growth, 1994 (A) and 1996 (B), respectively. (Standard uncertainty bars shown.)

\section{Anthropogenic Variations; "Trees Pollute"}

The achievement of high precision, low background counting, discussed in Sec. 3, led also to the first isotopic evidence of global pollution with fossil $\mathrm{CO}_{2}$ named the "Suess Effect," after its discoverer. A dramatic monotonic drop in the ${ }^{14} \mathrm{C} /{ }^{12} \mathrm{C}$ ratio in tree rings beginning in the late 19th century, reflecting the 

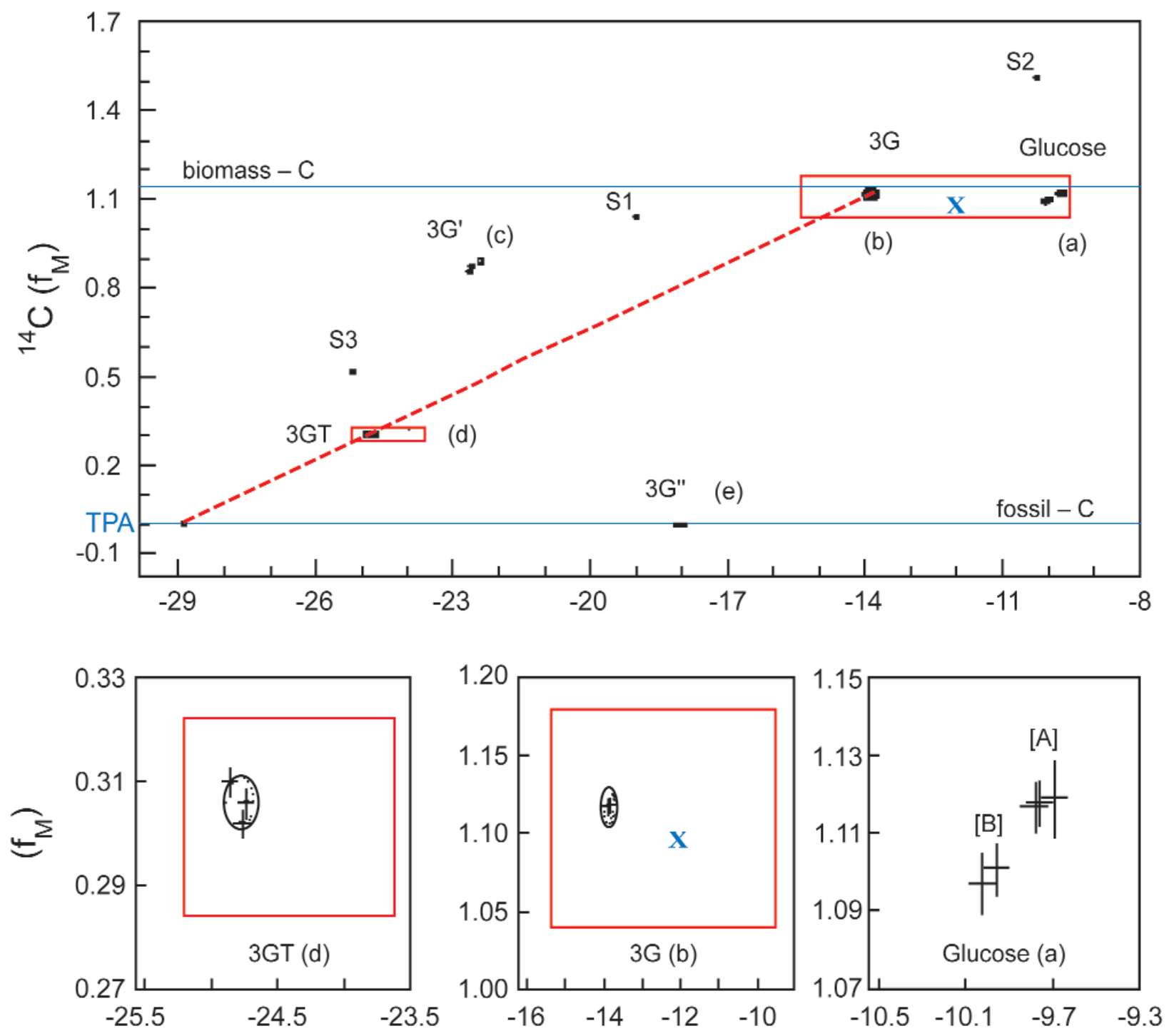

\section{$\delta^{13} \mathrm{C}$ (per mil)}

Fig. 10. Unique Isotopic Signatures: the ${ }^{14} \mathrm{C}-{ }^{13} \mathrm{C}$ plane [25]. The main panel shows dual isotopic signatures f:or (1) NIST (S1, S3) and IAEA (S2) traceability standards, and (2) glucose from biomass (a), the new bio-sourced monomer 3G (b) (from cornstarch), the resulting copolymer 3GT (d), and pre-existing products $3 \mathrm{G}^{\prime}, 3 \mathrm{G}^{\prime \prime}$ (c, e). Expanded views of the authentication regions (red rectangles) for the copolymer (left) and monomer (center) are given in the bottom panels, plus $\approx 10$-fold expansion (right) of the isotopic data for independent batches $(\mathrm{A}, \mathrm{B}$ ) of a biomass feedstock (glucose from corn). The blue " $x$ " represents a blind (3G) validation sample.

use of coal during the Industrial Revolution, showed a $2.5 \%$ fossil carbon dilution effect by the 1950s (Ref. [12], p. 289), after which it was eclipsed by the vast injection of "bomb" carbon. Thus began still another field of ${ }^{14} \mathrm{C}$ science: the investigation of anthropogenic variations, particularly as related to environmental pollution.

\subsection{Fossil-Biomass Carbon Source Apportionment}

Research on more specific local or even regional carbonaceous pollution began slowly, because of the massive samples required. Heroic sampling efforts in the late 1950s demonstrated the principle by measurements of particulate carbon pollution in U.S. urban atmospheres $[26,27]$. After a lapse of two decades, 


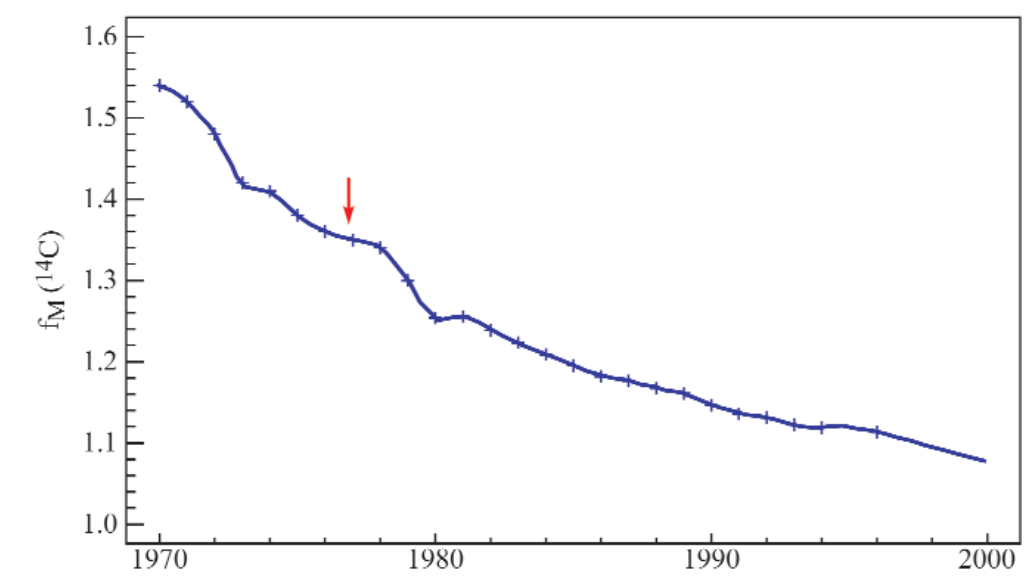

Fig. 11. Short term ${ }^{14} \mathrm{C}$ "decay" curve, representing geochemical relaxation of excess atmospheric ${ }^{14} \mathrm{C}$ from nuclear testing [Levin et al., in (Ref. [19]; Ref. [20], Chap. 31). Information critical for the discussion in Sec. 7.2.1 is indicated by the arrow-namely, the sampling date and corresponding biomass ${ }^{14} \mathrm{C}$ enrichment for SRM 1649a (urban dust).

research in this area was renewed by the author, stimulated by a 1975 article in Science reporting that the culprit for a severe case of urban pollution in tidewater Virginia might be hydrocarbon emissions from trees [28]. The evidence was chemical and controvertible: plausible, but circumstantial evidence suggested that the air pollution was due to hydrocarbon emissions from trees rather from automobile exhaust or evaporation from nearby industrial and military storage tanks. The article concluded that "the relatively unsophisticated monitoring of [organic] pollutant concentrations ... will rarely be of value in identifying [pollutant] sources ..." Recognizing immediately that ${ }^{14} \mathrm{C}$ could function as an undisputed discriminator, we decided to design miniature low level counters, capable of measuring just $10 \mathrm{mg}$ carbon samples, more than two orders of magnitude smaller than those used in the two earlier studies. Apart from forest fires, we found that the trees were not the prime culprits, except for the case where humans were using the trees for fuel! A review of research in this area in the ensuing 20 years is given in Ref. [29].

One illustration of ${ }^{14} \mathrm{C}$ aerosol science is given in Fig. 12. It is drawn from perhaps the most extensive study to date of urban particulate pollution using ${ }^{14} \mathrm{C}$. The multi-year, multidisciplinary study of the origins of mutagenic aerosols in the atmospheres of several U.S. cities, focussed on Albuquerque, New Mexico during the winter of 1984-1985. The photos show the tremendous impact on visibility from particulate pollution from rush hour traffic. Results of the two month study of particulate carbon proved that daytime pollution (up to $\approx 65 \%$ ) was dominated by motor vehicle emissions (fossil carbon), and nighttime pollution (up to $\approx 95 \%$ ), by residential woodburning (biomass carbon), with the mutagenicity (potency) of the motor vehicle particles more severe by a factor of three [30] Particulate carbon aerosols are now widely recognized as an extreme health hazard in a number of U.S. cities; and except for periods dominated by wildfires, major studies including ${ }^{14} \mathrm{C}$ measurements have produced incontrovertible evidence that the urban episodes are dominated by fossil carbon, largely from motor vehicle exhaust [31].

Quantitative apportionment of natural and anthropogenic sources of particulate carbon, methane, carbon monoxide, and volatile organic ozone precursors in the atmosphere, meanwhile, has seen a significant expansion thanks to the sensitivity enhancement of accelerator mass spectrometry (AMS) [32, 33]. Most recently, with the emergence of micromolar ${ }^{14} \mathrm{C}$ AMS, and GC/AMS, the ability to "date" individual chemical fractions in small samples is having important impacts on both artifact age accuracy, and our understanding of perturbations of the human and natural environments by fossil and biomass carbonaceous species. (See Section 7). 


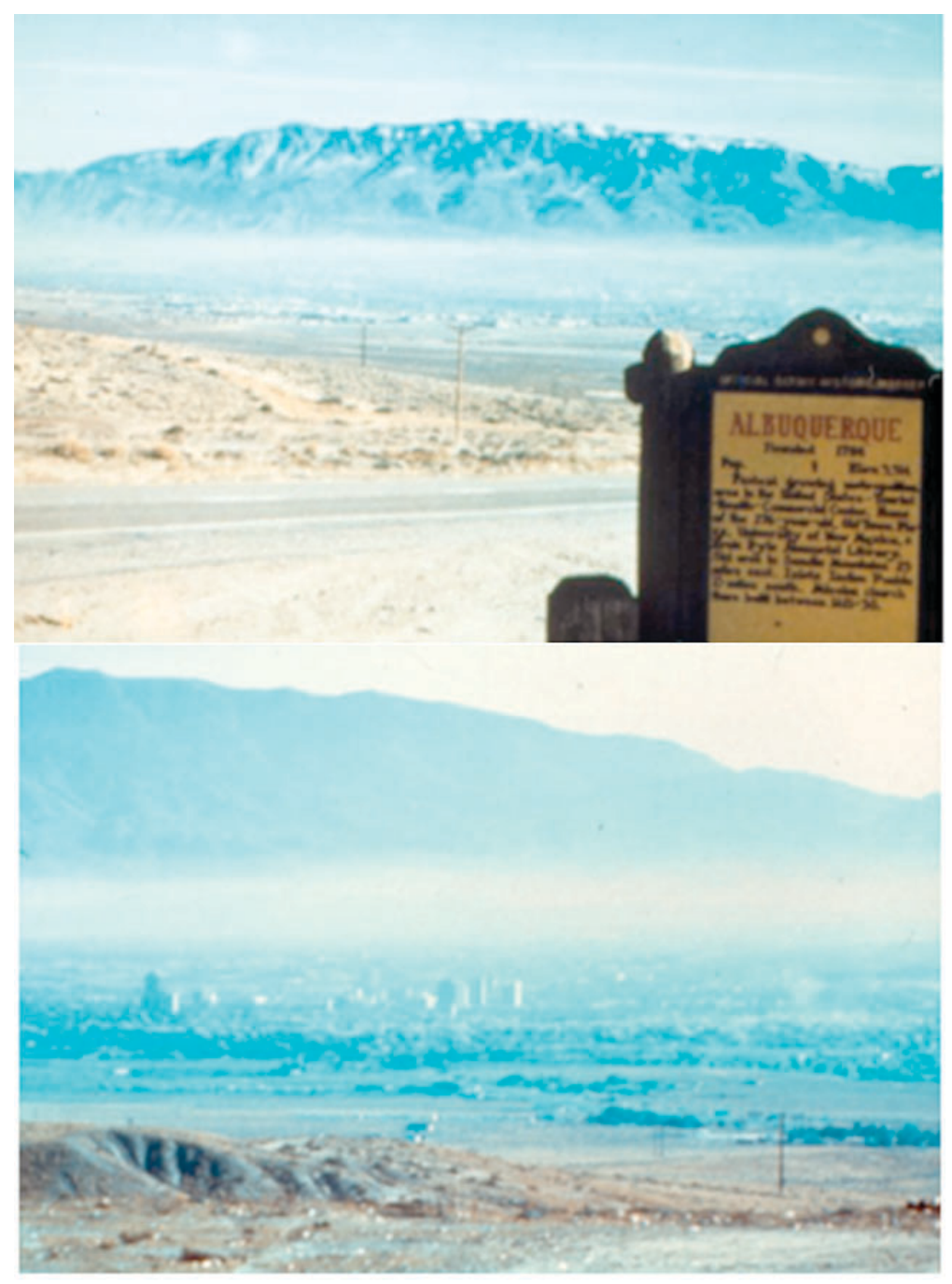

Fig. 12. Anthropogenic ${ }^{14} \mathrm{C}$ variations: fossil-biomass carbon apportionment of particulate air pollution in Albuquerque, New Mexico. (Photos showing visibility reduction in early morning (top) and mid-afternoon (bottom) are courtesy of R .K. Stevens [30].). ${ }^{14} \mathrm{C}$ measurements quantified atmospheric soot from motor vehicles and residential woodburning, and helped apportion concomitant data on particulate mutagenicity. 


\section{Accelerator Mass Spectrometry}

\subsection{The Invention}

The second revolution in ${ }^{14} \mathrm{C}$ measurement science was the discovery of a means to count ${ }^{14} \mathrm{C}$ atoms, as opposed to ${ }^{14} \mathrm{C}$ decays (beta particles). The potential impact on sensitivity was early recognized: inverting the first order nuclear decay relation, one finds that the ratio of the number of ${ }^{14} \mathrm{C}$ atoms to the number of ${ }^{14} \mathrm{C}$ decays for any given sample is simply $(\tau / t)$, where $\tau$ is the mean life $\left(8270\right.$ a for $\left.{ }^{14} \mathrm{C}\right)$, and $t$ is the counting time used for measurement of the disintegrations. Allowing for the difference in relative detection efficiency between AMS and low-level counting, and setting $t$ to $2 \mathrm{~d}$, gives a sensitivity enhancement of roughly $10^{4}$, in favor of AMS. This implies a dating capability of submilligram amounts of modern carbon.

The prize of radiocarbon dating at the milligram level was so great that major efforts were made to refine mass spectrometric techniques to render the $1.2 \times 10^{-12}{ }^{14} \mathrm{C} /{ }^{12} \mathrm{C}$ ratio of modern carbon measurable; but, like Libby's initial attempt to count natural radiocarbon (without enrichment), natural ${ }^{14} \mathrm{C}$ proved unmeasurable by conventional mass spectrometry. Impediments from molecular ions and the extremely close isobar $\left({ }^{14} \mathrm{~N}: \Delta m / m=1.2 \times 10^{-5}\right)$ were overwhelming. Success came in 1977, however, when high energy (megavolt) nuclear accelerators were used as atomic ion mass spectrometers [34-36]. Two measurement ideas held the key: (1) Negative carbon ions are produced by a sputter ion source, using graphite as the target. (2) Following low energy mass selection, atomic and molecular negative ions are injected into an accelerator tube with a megavolt potential. The major isobar is eliminated because nitrogen does not form a stable negative ion. Passage of the high energy ions through a stripper gas or foil destroys all molecular ions through the "coulomb explosion," leaving only atomic carbon ions in the +3 or +4 charge state. ${ }^{14} \mathrm{C} /{ }^{12} \mathrm{C}$ ratio measurements down to ca. $10^{-15}$ are thus made possible. Typical sample sizes are $0.5 \mathrm{mg}$ to $1 \mathrm{mg}$; modern carbon yields 10000 counts in just a few minutes; and instrument backgrounds are negligible $(\leq 0.2 \%$ modern, equivalent to a ${ }^{14} \mathrm{C}$ age of $\geq 50000$ years $\mathrm{BP}$ ).

A diagram of the accelerator at one of the leading facilities is given in Fig. 13 [37]. The dramatic impact of high energy (atomic ion) mass spectrometry is shown in Fig. 14, where it is clear that natural ${ }^{14} \mathrm{C}$ is quite unmeasurable by low energy (conventional) mass spectrometry due to molecular ions exceeding the ${ }^{14} \mathrm{C}$ signal by more than eight orders of magnitude (Ref. [20], Chap. 16]! Excellent reviews of the history, principles, and applications of AMS are given in Ref. [20] by H. Gove (Chap. 15) and R. Beukens (Chap. 16).

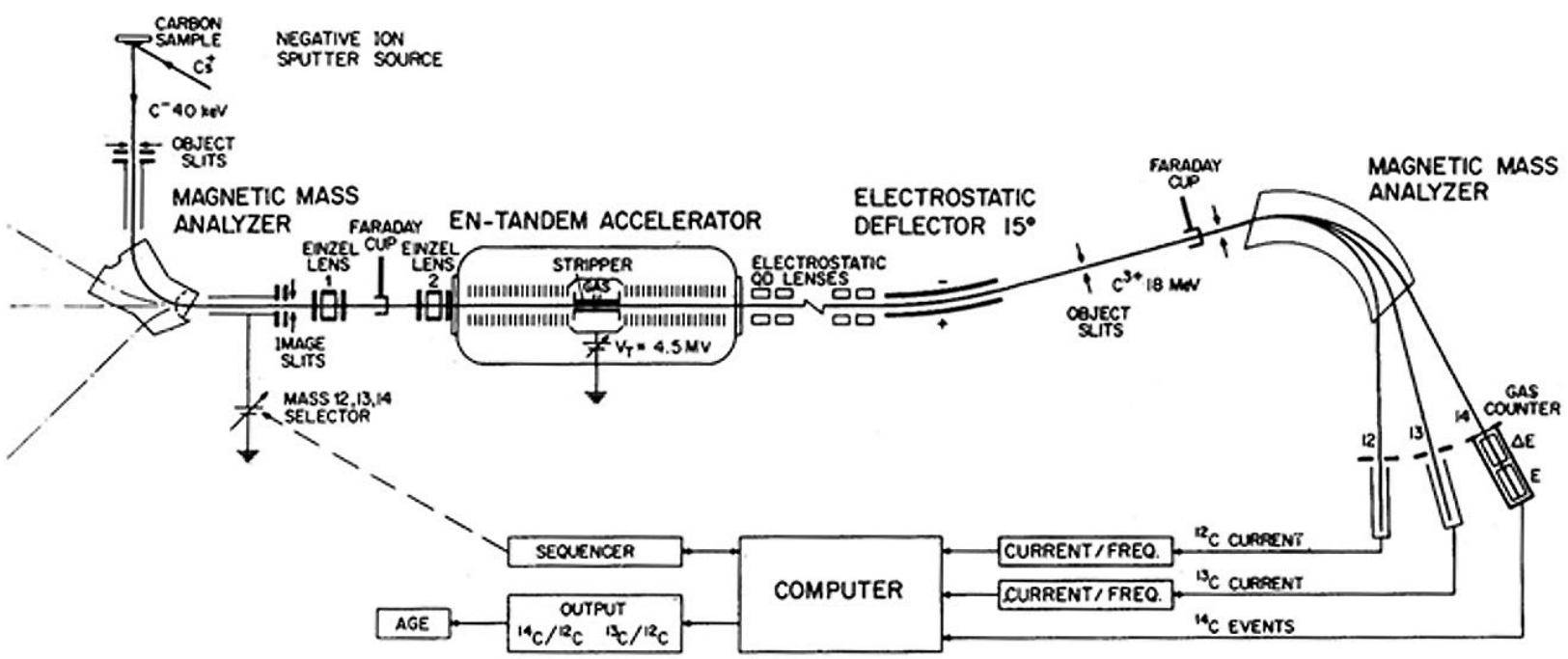

Fig. 13. AMS: tandem accelerator at ETH, Zürich. Negative carbon ions, produced with a Cs ${ }^{+}$sputter ion source, undergo low energy mass resolution and then are injected into the $4.5 \mathrm{MV}$ accelerator tube. Molecular ions are destroyed by the stripper gas, and emerging $18 \mathrm{MeV} \mathrm{C}^{+3}$ beams of ${ }^{12} \mathrm{C},{ }^{13} \mathrm{C}$, and ${ }^{14} \mathrm{C}$ are mass analyzed and measured in current (stable $\mathrm{C}$ ions) and event $\left({ }^{14} \mathrm{C}\right.$ ions) detectors [37]. 


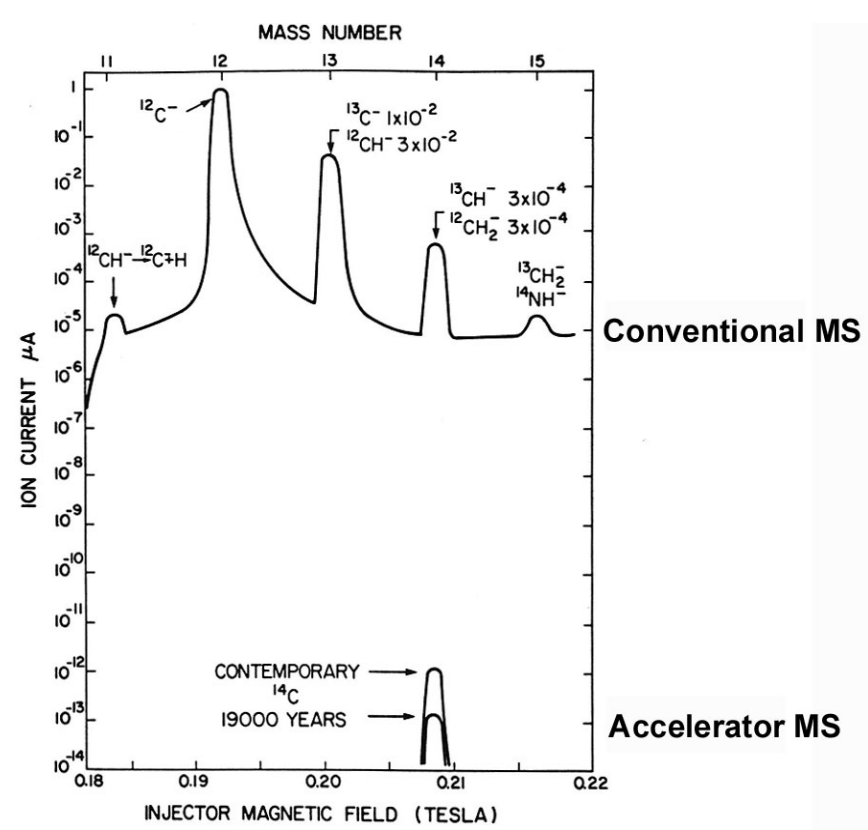

Fig. 14. Conventional (top) vs accelerator (high energy) (bottom) mass spectrometry: ${ }^{14} \mathrm{C} /{ }^{12} \mathrm{C}$ sensitivity is enhanced by more than eight orders of magnitude through destruction of molecular ions (and unstable $\mathrm{N}$ ) (Ref. [20], Chap. 16).

As noted in the reviews by Gove and Beukens, the AMS revolution has extended well beyond ${ }^{14} \mathrm{C}$, spawning a totally new research area in long-lived isotopic and ultra trace stable cosmo- and geo-chemistry and physics through its capability to measure ${ }^{3} \mathrm{H},{ }^{14} \mathrm{C},{ }^{26} \mathrm{Al}$, ${ }^{36} \mathrm{Cl},{ }^{41} \mathrm{Ca}$, and ${ }^{129} \mathrm{I}$, and most recently, selected actinides.

Within one year of the publications announcing successful ${ }^{14} \mathrm{C}$ AMS, another continuing series of international conferences was born. The first international AMS conference took place in 1978 in Rochester, New York. These conferences have continued on a triennial basis, with each proceedings occupying a special AMS conference issue of the journal, Nuclear Instruments and Methods in Physics Research.

\subsection{The Shroud of Turin}

The radiocarbon dating of the Turin Shroud is arguably the best known dating application of accelerator mass spectrometry, at least to the lay public. It could not, or at least it would not have taken place without AMS, because most decay (beta) counting techniques would have consumed a significant fraction of this artifact. Although still a destructive analytical technique, AMS required only "a postage stamp" amount of the linen cloth (Ref. [20], Chap. 15). This particular exercise is having a metrological impact well beyond the radiocarbon date, per se. This is shown, in part, by widely accepted statements (1) concerning scientific investigations of the Shroud, and (2) following publication of the Nature article announcing radiocarbon dating results (Fig. 15; Ref. [38]).

1: "The Shroud of Turin is the single, most studied artifact in human history."

2: "The Nature $\left({ }^{14} \mathrm{C}\right)$ article has had more impact on Shroud research than any other paper ever written on the subject."

The article, which was prepared by three of the most prestigious AMS laboratories, is available to the general public on the web (www.shroud.com/nature.htm). Together with public television [39], it is helping to create a broad awareness and understanding of the nature and importance of the AMS measurement capability. Secondly, because of controversy surrounding the meaning of the radiocarbon result, measurement aspects of artifact dating have been given intense scrutiny. Such scrutiny is quite positive, for it gives the possibility of added insight into unsuspected phenomena and sources of measurement uncertainty.

The Turin Shroud is believed by many to be the burial cloth of Christ. The documented record, however, goes back only to the Middle Ages, to Lirey, France (ca. $1353 \mathrm{AD}$ ) with the first firm date being 1357 AD when it was displayed in a Lirey church. 


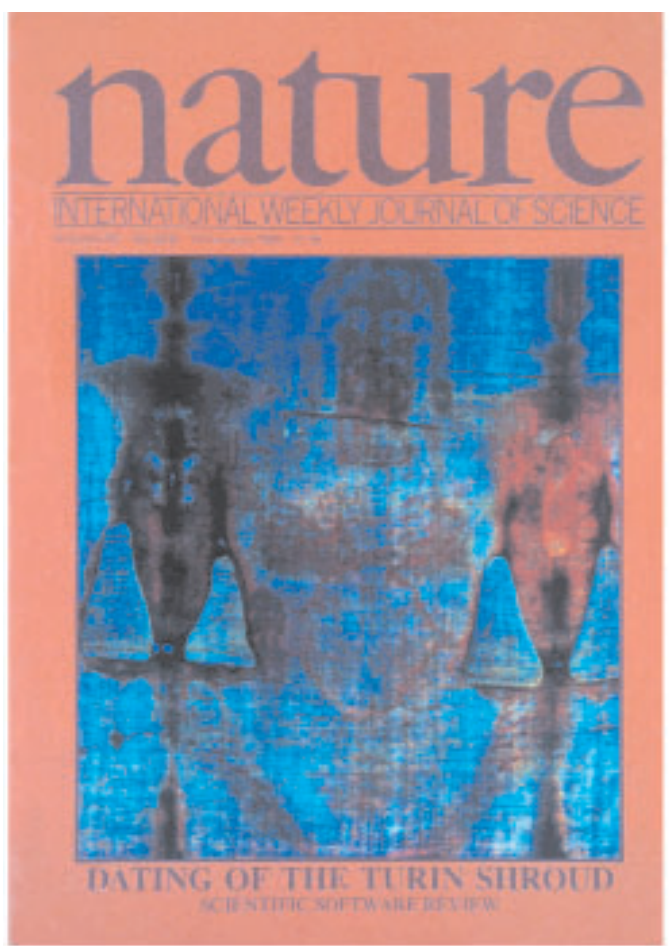

(a)

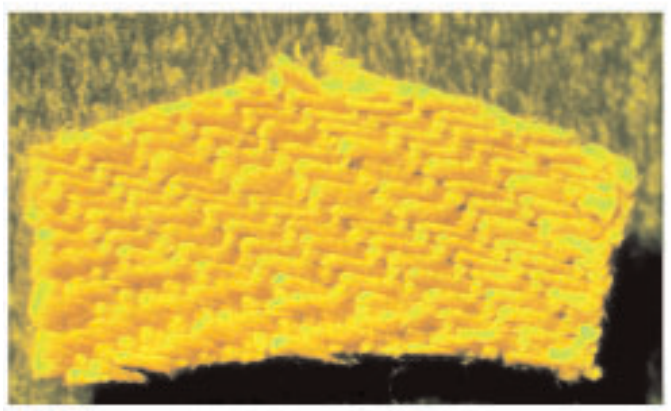

(b)

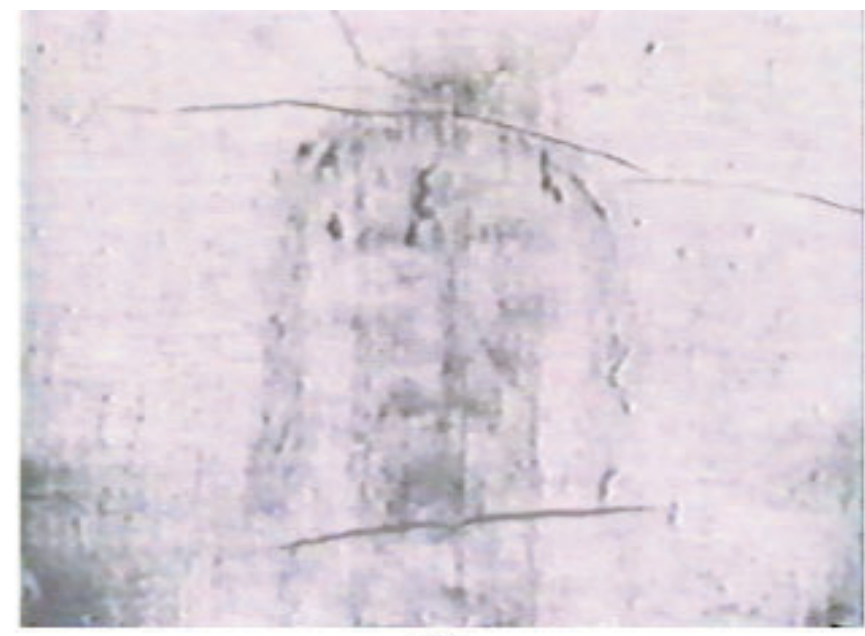

(c)

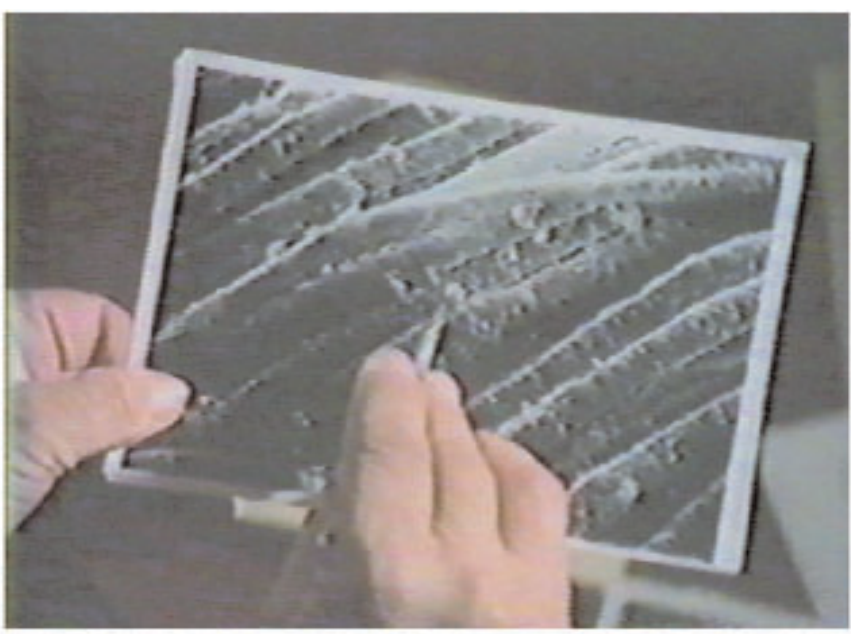

(d)

Fig. 15. The Turin Shroud. Shown in the montage are: (15a, upper left), the cover of the issue of Nature (16 February 1989) reporting the results of the ${ }^{14} \mathrm{C}$ measurements by AMS laboratories in Tucson, Zürich, and Oxford; and three singular features of the artifact: (15b, lower left), the $\approx 50 \mathrm{mg}$ dating sample received by the Tucson laboratory, showing the distinctive weave (3:1 herringbone twill), with dimensions about $1 \mathrm{~cm} \times 0.5 \mathrm{~cm} ;(15 \mathrm{c}$, upper right), the characteristic negative image, considered by some as a remarkable piece of mediaeval art; and (15d, lower right), a microphotograph by Max Frei showing individual fibers supporting pollen grains of presumed unique origin [38, 39]. 
Radiocarbon dating was seen immediately as a definitive method to decide whether the "Lirey Shroud" could have come from flax grown in the 1st century AD. The Shroud image, considered by some to be the skilled work of a mediaeval artist, shows a full length image of a crucified man; but as a negative image [Fig. $15 \mathrm{c}] .{ }^{9}$ Prior to the AMS measurements, the Shroud was subject to intensive examination by photography, spectroscopy, art and textile analysis, and palynology [3840]. The unique herringbone twill [Fig. 15b] is considered consistent with a 1st Century date; and pollen grains found on the cloth [Fig. 15d] are stated by Max Frei to have originated from a plant found only in the region of Jerusalem. Radiocarbon dating of the cloth, however, yielded a result of 1262 to 1384 AD (95\% confidence interval) [38].

Apart from sampling, ${ }^{10}$ the AMS measurements were performed taking the strictest quality control measures.

\footnotetext{
${ }^{9}$ Figure $15 \mathrm{c}$ and $15 \mathrm{~d}$ images are from the documentary prepared by the British Broadcasting Corporation which is hereby acknowledged [39]; Fig. 15b is courtesy of D. J. Donahue.
}

${ }^{10}$ The critical, non-AMS issue relates to sample validity. The originally agreed upon sampling protocol was to have involved seven laboratories, two measurement techniques (decay and atom [AMS] counting), and multiple samples representing different regions of the cloth. Shortly before the event, however, the scheme was changed to restrict the number of laboratories (all AMS) and the number of samples to three, all taken from the same location. The sampling location, near a corner of the Shroud, and near an area damaged by the fire of $1532 \mathrm{AD}$, is considered an unfortunate choice, because of the possibility of exogenous carbon from the fire, repairs, and organic contamination from handling through the ages [40, 41].

Organic contamination cannot be dismissed. Recent observations indicate the presence of a bacterially-induced "bioplastic" coating on Shroud fibers, as has sometimes been found on mummy wrapping fabric (leading to erroneous dates). According to [42] (Gove, et al.), such bioplastic contamination would not have been removed by the conventional pre-treatment methods applied to the Shroud samples. Qualitatively, such contamination would lead to a more recent date; quantitatively, if the contamination were all from the 16th Century, it would need to represent roughly $70 \%$ of the carbon present, to shift a first century date to the observed result. (For recent, late 20th Century contamination, roughly $40 \%$ contamination carbon would be required.) In a 2002 review article posted to the shroud website, www.shroud.com/pdfs/rogers2.pdf, [38], Rogers and Arnoldi question the bioplastic hypothesis, on the basis of detailed chemical analysis of fibers from the "Raes sample" which was taken from a region adjacent to that of the ${ }^{14} \mathrm{C}$ samples. Quantitatively, these authors suggest that the coating would contribute only a few percent to the sample carbon; qualitatively, they believe that it is a polysaccharide gum (probably Gum Arabic) that would be removed by the ${ }^{14} \mathrm{C}$ pretreatment chemistry. Nevertheless, Rogers and Arnoldi question the validity of the ${ }^{14} \mathrm{C}$ sample, partly because of the presence of cotton and other chemical differences between the adjacent (Raes) sample and the main shroud material.
Three highly competent laboratories were selected: the University of Arizona, Oxford University, and the Swiss Federal Institute of Technology [ETH] in Zürich. Samples of the Shroud, plus three control samples of known age, were distributed blind to the three laboratories. Control of this operation (distribution of samples, collection of results) was the responsibility of Michael Tite of the British Museum. The accuracy and precision of the interlaboratory data for the control samples were outstanding, leaving no doubt as to the quality of the AMS measurement technique (Fig. 16). Sample-1 (Shroud) results, however, were just marginally consistent among the three laboratories, prompting the authors of Ref. [38] to state that "it is unlikely that the errors quoted by the laboratories for sample-1 fully reflect the overall scatter." Consistent with the discussion in Sec. 2, the ${ }^{14} \mathrm{C}$ age measurements are reported in " ${ }^{14} \mathrm{C}$ years BP." Transformation of these ages to calendar ages must take into account the natural ${ }^{14} \mathrm{C}$ variations, using the dendrochronological calibration curve [13]. The transformation is shown in Fig. 17, which demonstrates also an interesting aspect of the non-monotonic calibration function: namely, exclusion of the period between $1312 \mathrm{AD}$ and $1353 \mathrm{AD}$ from the $95 \%$ confidence interval. In addition, an interesting link exists between this figure and Fig. 6 (Maunder Minimum), in that the same solaractivity-induced ${ }^{14} \mathrm{C}$ variations are represented. A comparison of the two figures shows that the radiocarbon date (691 BP), near the end of a significant calibration curve protrusion (Fig. 17), corresponds to the end of the 13th century warm period having high solar activity (Fig. 6).

Consistency of the AMS results with the existing (Lirey) documentation seems compelling, but a wave of questioning has followed - not of the AMS method, but of possible artifacts that could have affected the linen and invalidated the ${ }^{14} \mathrm{C}$ result (Ref. [40], Chap. 1, Refs. [41], [42]). A sampling of the creative hypotheses put forward is given in Table 2. The first, for example, is based on the premise that nuclear reactions involving the substantial amount of deuterium contained in a human body could produce neutrons, which might then produce excess ${ }^{14} \mathrm{C}$ through the $(\mathrm{n}, \mathrm{p})$ reaction, making the age too young. The proposed deuteron reactions, however, are either qualitatively or quantitatively inaccurate - barring an unnatural burst of high energy photons (photofission). The third proposal raises the question of non-contemporaneous organic matterwhether from incompletely removed carbon contamination from "oil, wax, tears, and smoke" that the cloth had been exposed to, or from bacterial attack and 


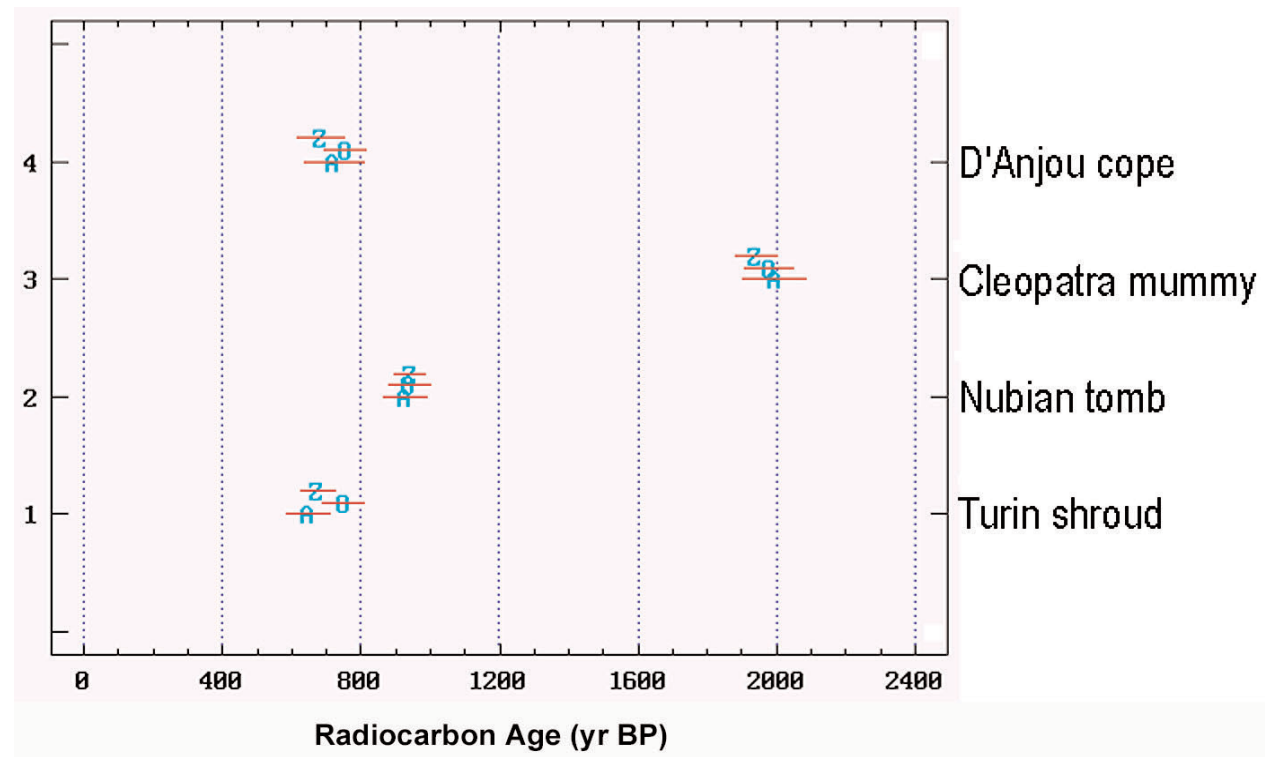

Fig. 16. AMS ${ }^{14} \mathrm{C}$ dating results ("blind") for the Turin Shroud (sample-1) and three control samples of known age (samples-2,3,4), from the three AMS laboratories: Z (Zürich), O (Oxford), and A (Arizona). Dates are expressed as "Radiocarbon Years" before present (BP); uncertainties represent $95 \%$ confidence intervals [38].

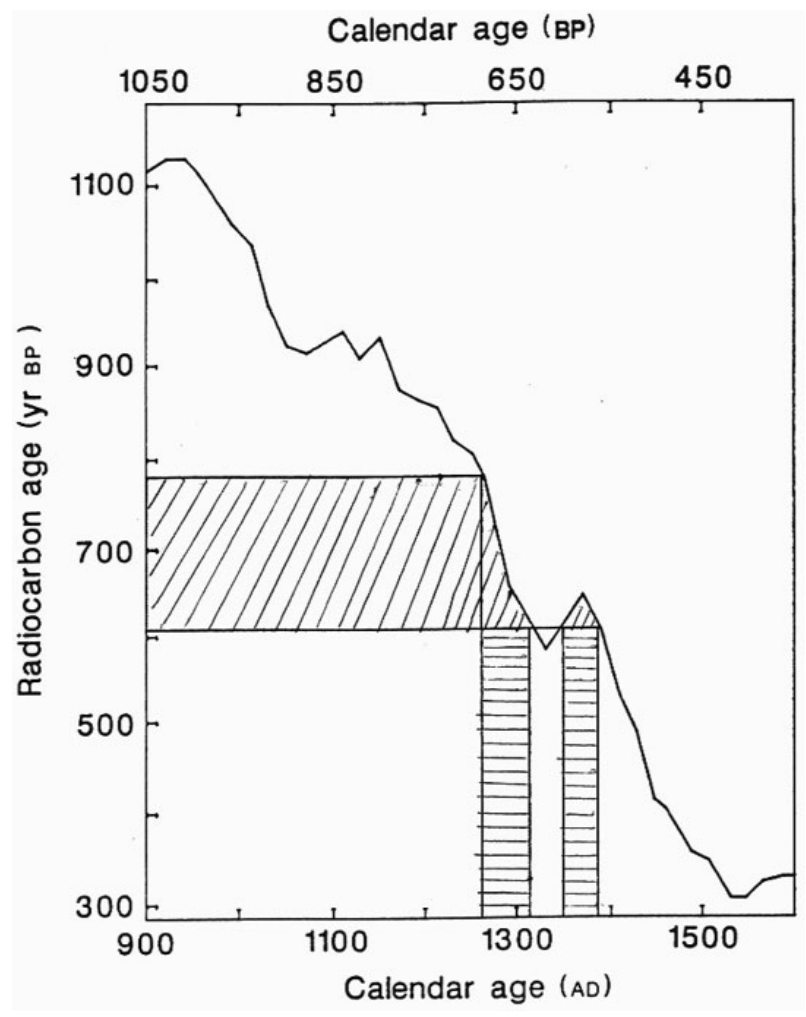

Fig. 17. Transformation of the Radiocarbon Age (BP) to the Calendar Age (AD) of the Shroud. The ${ }^{14} \mathrm{C}$ age $(95 \% \mathrm{CI})$ of $(691 \pm 31)$ $\mathrm{BP}$ corresponds to a two-valued calendar age as a result of the nonmonotonic radiocarbon dating calibration curve. As indicated in the figure, the projected calendar age ranges are: (1262-1312) AD and (1353-1384) AD [38]. 
Table 2. Creative Hypotheses

- Excess ${ }^{14} \mathrm{C}$ from deuterium spontaneous fission; cold fusion

- ${ }^{14} \mathrm{C}$ isotopic fractionation/ exchange (fire of $1532 \mathrm{AD}$ ) biased sampling; "age" depends on location

- Bioplastic coating; non-contemporaneous with linen pretreatment chemistry

deposit over the ages. Apart from the effects of such factors on the Shroud, the issue of organic reactions and non-contemporaneous contamination of ancient materials can be a very serious and complex matter, deserving quantitative investigation of the possible impacts on measurement accuracy. ${ }^{10}$ Research questions of this sort, including the classic problem of dating ancient bone, form one of the key stimuli for the development of "molecular dating" - the topic of the following section.

\section{Emergence of $\boldsymbol{\mu}$-Molar ${ }^{14} \mathrm{C}$ Metrology}

Radiocarbon metrology is at the very moment in the midst of still another revolution, involving the dating (or isotopic speciation) of pure chemical fractions: "molecular dating." For trace species, such as polycyclic aromatic hydrocarbons (PAHs), or remote, low concentration samples, such as the soot or pollen in the free troposphere or in ice cores, the sensitivity of AMS is challenged to its ultimate. In order to understand the nature of the challenge it is interesting to consider the limiting factors. In a recent study it was shown that $10 \%$ Poisson "error" (standard uncertainty) can be achieved with $0.9 \mu \mathrm{g}$ modern carbon, whereas machine background is equivalent to $0.2 \mu \mathrm{g}$ or less [43]. Sample processing blanks, however, may range from $1 \mu \mathrm{g}$ to $15 \mu \mathrm{g}$ or more, and they may consist of both biomass carbon and fossil carbon [44]. Thus, the ultimate limiting factor for very small sample AMS is the overall isotopic-chemical blank. Environmental studies of ${ }^{14} \mathrm{C}$ in individual chemical compounds can be successful at the $1 \mu \mathrm{g}$ to $10 \mu \mathrm{g}$ level, but only with stringent control of the variability of the blank. This is in sharp contrast with small sample, low-level counting where the Poisson modern carbon limit (ca. $3 \mathrm{mg}$ ) and background limit (ca. $5 \mathrm{mg}$ equivalent) far exceed the typical sample preparation blank (ca. $40 \mu \mathrm{g}$ ) [29]. ${ }^{11}$

Some illustrations of pure compound "dating" by NIST and collaborators are given in Table 3. The first item refers to the aforementioned $1 \mu \mathrm{g}$ capability, using "dilution AMS." For thermally stable species such as soot and pollen, we have the possibility of controlling the sample preparation blank to less than $0.2 \mu \mathrm{g}$ by applying a "thermal discriminator" at a critical stage of the process. Microgram level ${ }^{14} \mathrm{C}$ soot studies have already been successful in Greenland snow; and pollen studies hold great promise for ice core dating, and perhaps even for dating the pollen found by Max Frei on the Turin Shroud. ${ }^{12}$ An important measurement issue for ice core pollen relates to the amount needed for a given dating precision. To give a rough estimate: assuming $50 \mathrm{ng}$ carbon per pollen grain, a pollen age of 2000 years, and $5 \%$ Poisson imprecision ( $\sigma \approx 400$ years); one would need to collect about 100 pollen grains. This might be accomplished in a few hours, using the "hand picking" microscope technique of Long et al. [48].

Table 3. Molecular Dating $\left({ }^{14} \mathrm{C}\right.$ AMS at the microgram level $)$

- Dilution AMS quantifies $0.9 \mu \mathrm{g}$ modern carbon (1999)

- soot/ pollen blank controllable to $\sim 0.2 \mu \mathrm{g}(\sigma \approx 60 \mathrm{ng})$

- challenge: dating pure pollen grains from the Shroud

- Fossil and biomass aerosol sources characterized in remote atmosphere/ cryosphere ( $2.9 \mu \mathrm{g}$ biomass soot quantified)

- Individual amino acids dated in mammoth bones (LC/AMS)

- Individual polycyclic aromatic hydrocarbons dated in atmospheric particles and marine sediment (GC/AMS)

\footnotetext{
${ }^{11}$ There is a profound difference between background-limited decay counting and blank-limited AMS, that may not be widely appreciated. Although the ultimate limitation in each case is " $\mathrm{B}$ " variability, when $B$ represents the instrumental background it tends to be reasonably well controlled, and under the best of circumstances, Poissonian [45]. An extra degree of caution is needed, however, when the limiting " $\mathrm{B}$ " is an isotopic-chemical blank. At best, it might be assumed normal; then replicate-based detection tests and confidence intervals can be constructed using Student's-t. If the blank does not represent a homogeneous or stationary state (as a reagent blank, well-mixed environmental or biological compartment, etc.), such tests and intervals can be totally misleading. Non-stationary blanks may exhibit (geochemically meaningful) structure, or they may be erratic, reflecting a transient source of contamination [46].

${ }^{12}$ Molecular dating" of the pure cellulose fraction of the Shroud, or of the associated pollen, could furnish an interesting consistency test for the published radiocarbon date. It would be especially interesting to put a "time stamp" on pollen whose point of origin has already been ascribed to a location $10 \mathrm{~km}$ to $20 \mathrm{~km}$ east and west of Jerusalem [47]. Such measurements are made feasible by the reduction of requisite sample sizes by a factor of ten or more, from what AMS ${ }^{14} \mathrm{C}$ dating required sixteen years ago. The question of noncontemporaneous fiber from 16th Century repairs, for example, could be addressed by new ${ }^{14} \mathrm{C}$ measurements on just $100 \mu \mathrm{g}$ of fibers $(\approx 50,1 \mathrm{~cm}$ linen fibers) from the main part of the Shroud. The expected standard uncertainty would be equivalent to approximately 120 radiocarbon years ([43], Eq. 1).
} 


\subsection{Long-Range Transport of Fossil and Biomass Aerosol}

Ongoing multidisciplinary, multi-institutional research on soot particles in remote and paleo-atmospheres, which is absolutely dependent on the small sample dating capability, is indicated in Fig. 18. The upper portion of the figure relates to climate oriented research on the sources and transport of fossil and biomass aerosol to the remote Arctic [49]; the lower portion relates to atmospheric and paleoatmospheric research at Alpine high altitude stations and ice cores [50,51]. In the remainder of this section we present some of the highlights and measurement challenges of the first project, on the long-range transport of carbonaceous particles to Summit, Greenland.

Cooperative research on this project, between NIST and the Climate Change Research Center at the University of New Hampshire (UNH), began in 1994. It was catalyzed by the discovery of an unusually heavy loading of soot on one of the air filters used for ${ }^{7} \mathrm{Be}$ sampling at Summit, Greenland by Jack Dibb of UNH [52]. The Summit soot had been ascribed to the combination of intense boreal wildfire activity in the lower Hudson's Bay region of Canada and exceptional atmospheric transport to central Greenland. Measurement of ${ }^{14} \mathrm{C}$ in the filter sample yielded definitive evidence for biomass burning as the source of the soot. On one day only (5 August 1994), the biomass carbon increased by nearly an order of magnitude, with scarcely any change in the fossil carbon concentration on the filter. Supporting data for the origin of the biomass burning carbon came from backtrajectory analysis, AVHRR (infrared) satellite imagery of the source region, and TOMS (ultraviolet) satellite imagery that was able to chart the course of the soot particles from the source wildfires to Summit. The several parts of this remarkable event are assembled in Figs. 19, 20 [29,49,52]. ${ }^{13}$

Since snow and ice can serve as natural archives for atmospheric events, one may expect to find chemical

\footnotetext{
${ }^{13}$ The observed (Fig. 20) vs inferred (Fig. 19) paths of the smoke plume present an interesting contrast. The TOMS satellite image shows the smoke approaching the southern tip of Greenland on 3, 4 August 1994 and departing toward Iceland on 6 August. The backtrajectory model employed in Ref. [52] places the approach at a somewhat higher latitude, and of course provides no departure information.
}

evidence of prior years' fire seasons in snowpits, firn, and ultimately ice cores. This is illustrated in the upper right portion of Fig. 18, which shows depth profile sampling in a snowpit at Summit, overlaying an energy dispersive spectrum and SEM image of a char particle found near the 1994 fire horizon in a 1996 snowpit [29]. An organic tracer of conifer combustion, methyl dehydroabietate, was found also at the same depth [53].

Atmospheric science entered a new phase at Summit during the "Winter-Over" project (1997-1998) [54] For the first time, direct sampling of air and surface snow took place over the polar winter, extending from June 1997 to April 1998. A special achievement of micro-molar ${ }^{14} \mathrm{C}$ "dating" was the first seasonal data for carbonaceous particles, deposited with the surface snow. ${ }^{14}$ The seasonal record for biomass carbon particles, shown in Fig. 21, was striking [55]. The large spring peaks, in particular, consisted primarily of biomass carbon: $0.76(u=0.03)$ modern carbon mass fraction $\left(f_{\mathrm{M}}\right)$ for sample-1 (WO1), and $0.94(0.01)$ mass fraction for sample-8 (WO8). Beyond the fossilbiomass apportionment, however, lay questions about the nature and origin of the carbonaceous aerosol. Especially intriguing are contrasts between the samples showing summer [sample-4 (WO4)] and spring [sample-8 (WO8)] biomass-C maxima in Fig. 21. To explore these, a "multi-spectroscopic" approach was taken, through which insights and supporting evidence were derived from a variety of analytical techniques. Results for one of the microanalytical techniques employed, laser microprobe mass spectrometry (LAMMS), are shown in Fig. $22 .{ }^{15}$ The figure uses a principal component projection to summarize multivariate (multi-mass) contrasts between the summer and spring biomass peaks. It shows that the three summer (WO4) sub-samples tend to favor $\mathrm{C}_{n}^{-}$cluster ions (n-even), typical of condensed carbon structure (and graphite), whereas the three spring (WO8) sub-samples exhibit a more complex, oxygenated structure such as occurs with biopolymers.

\footnotetext{
${ }^{14}$ The micro-molar ${ }^{14} \mathrm{C}$ capability was essential for this work because of the extremely small concentrations of particulate carbon in the surface snow, especially during the winter $(<10 \mu \mathrm{g} \mathrm{C} / \mathrm{kg}$ snow $)$. ${ }^{15}$ Microanalytical methods, such as LAMMS, are crucial for gaining chemical insight on individual particles, or when only very small snow (or ice) samples of remote aerosols are available, or needed for high resolution studies. In contrast to the ng capability of the most sensitive bulk analysis techniques, LAMMS, can provide useful chemical data on as little as $20 \mathrm{pg}$ of carbon species [57].
} 


\section{Summit, Greenland}

- Particle (90\% C) from 1994 fire horizon

- Biomass-C aerosol seasonal cycle reported (2003) [6 to $40 \mu \mathrm{g} / \mathrm{kg}$ snow]
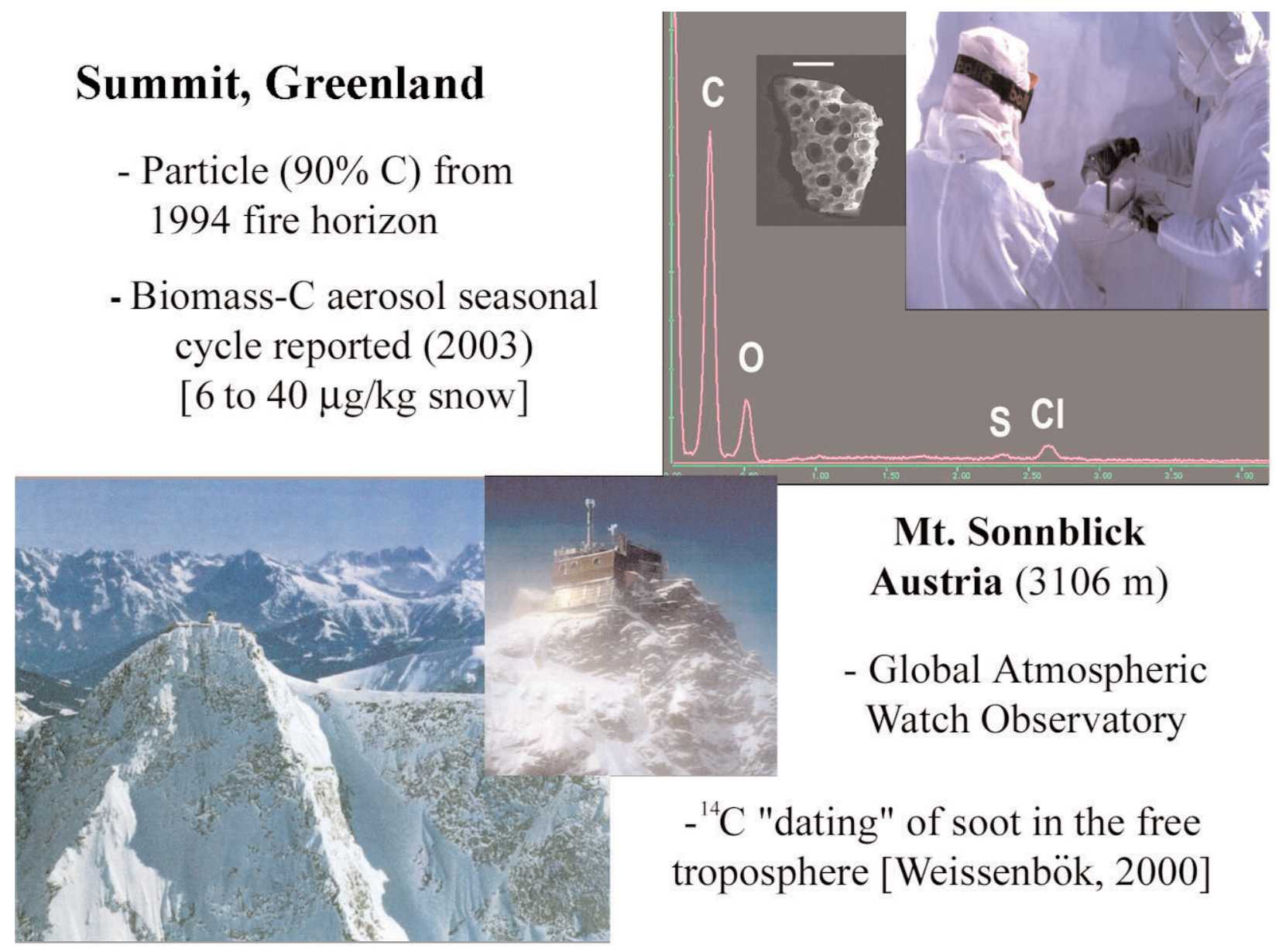

Mt. Sonnblick Austria (3106 m)

- Global Atmospheric Watch Observatory

$-{ }^{14} \mathrm{C}$ "dating" of soot in the free troposphere [Weissenbök, 2000]

Fig. 18. Submicromolar ${ }^{14} \mathrm{C}$ apportionment of anthropogenic and natural carbonaceous aerosols at remote sites in Europe and Greenland provides knowledge of their impacts on present and paleoclimate [49-51]. 


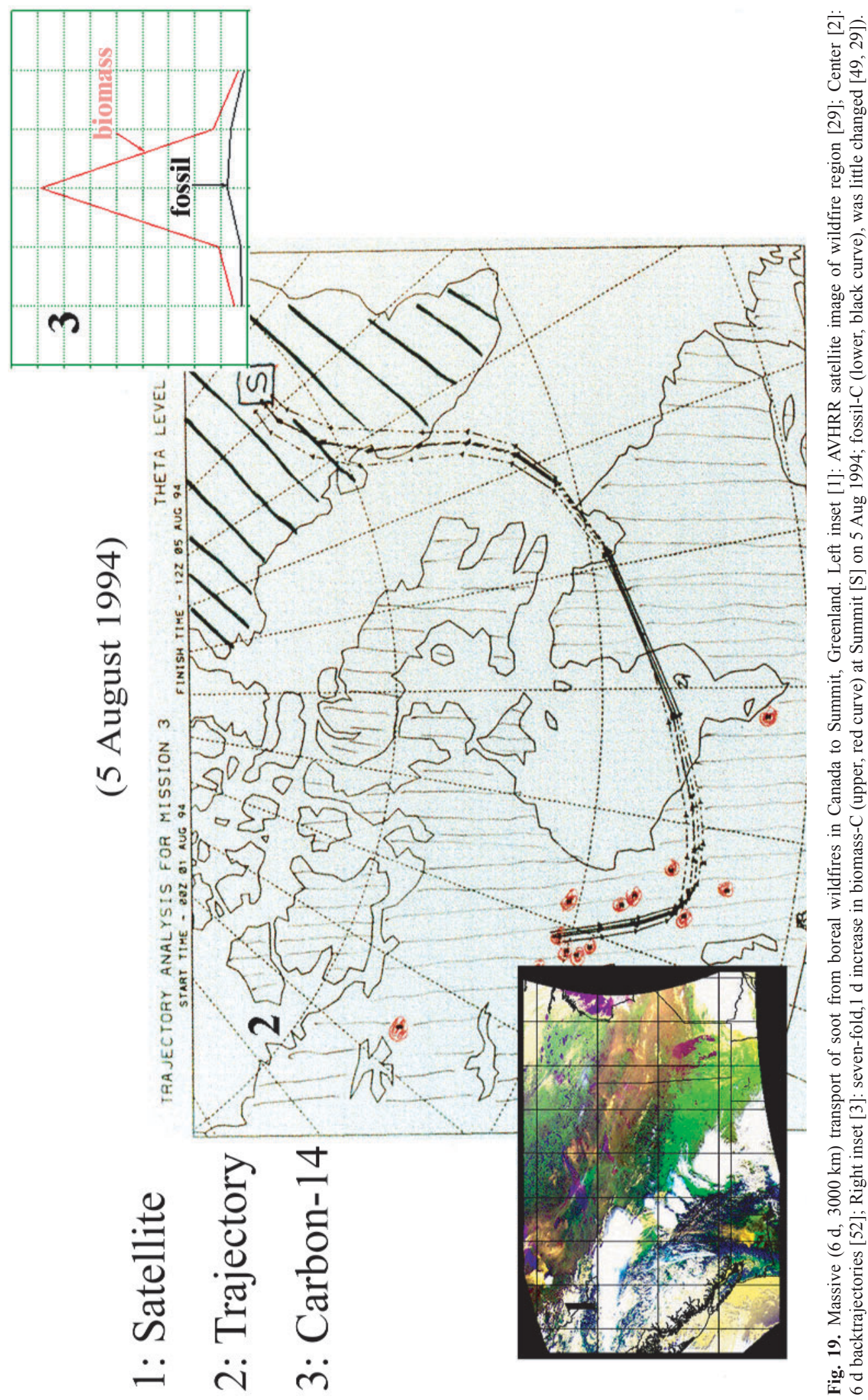




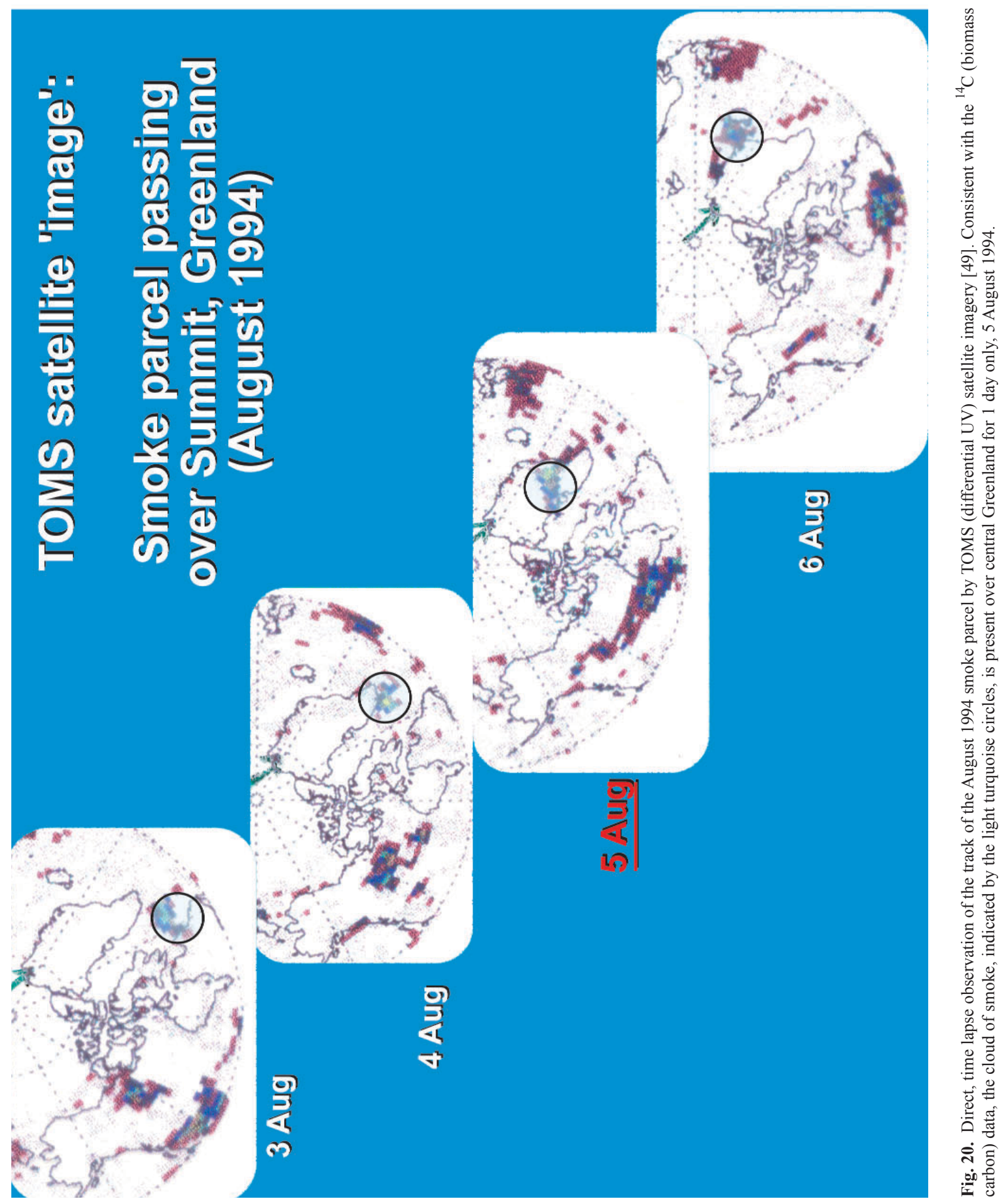




\section{Summit Snow -- Winter Over (1997-1998)}

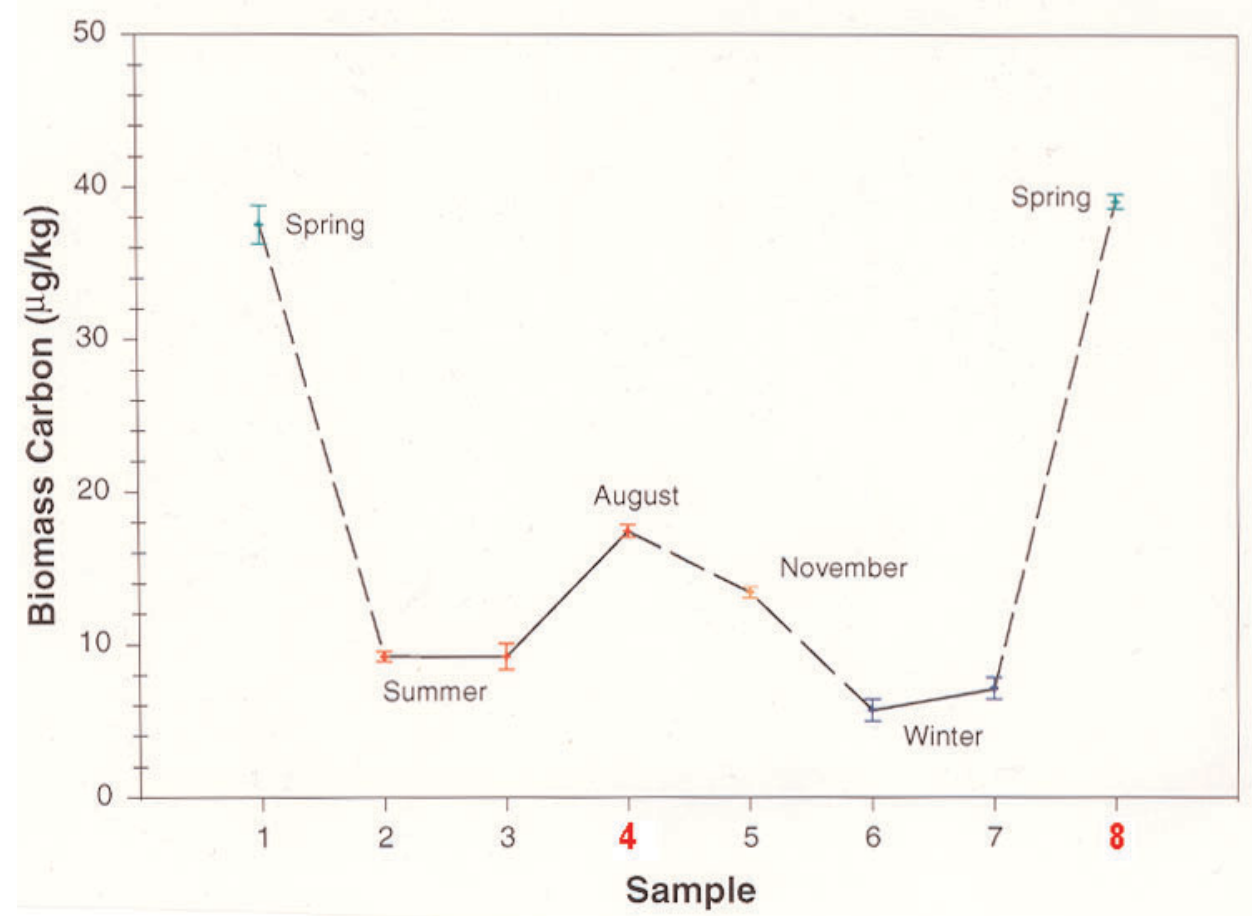

Fig. 21. First evidence of a seasonal pattern in biomass carbon aerosol in surface snow in central Greenland $[55,56]$. Fundamental differences were found between the biomass carbon peaks in summer (sample-4 [WO4]), and spring (sample-8 [WO8]) via "multi-spectroscopic" macro- and micro-chemical analysis.

Findings from other techniques:

- Thermal-optical analysis. Distinctive seasonal volatilization/decomposition patterns were seen as samples were heated in a stream on helium. The summer sample (WO4) had a predominant high temperature peak at $\approx 560^{\circ} \mathrm{C}$ and little evidence of charring (4\%), whereas the spring sample (WO8) had a predominant peak at $\approx 410{ }^{\circ} \mathrm{C}$ and major charring (19\%). Thermal analysis of a powdered wood (oak) reference material showed a thermal peak at the approximately same temperature as WO8, with $21 \%$ charring, implying the presence of a major cellulosic component in this sample.

- Ion chromatography. Fire tracers $\left(\mathrm{NH}_{4}^{+}, \mathrm{K}^{+}\right)$ accompanied WO4; soil tracers $\left(\mathrm{Ca}^{++}, \mathrm{Mg}^{++}\right)$ accompanied WO8

- Backtrajectories. For WO4, strong transport was indicated from regions of annual wildfires in the Canadian Northwest; for WO8, strong transport was indicated from the agricultural regions of the upper Midwest-both representing transport distances of some $8 \mathrm{Mm}$.
- Electron probe microanalysis. For WO4, up to $90 \% \mathrm{C}$ (mass fraction) was observed in individual, $\mu \mathrm{m}$ size particles, with $\mathrm{C}>\mathrm{O}$ for the most abundant (core) particles; for WO8, maximum C particles had a $\mathrm{C}: \mathrm{O}$ ratio consistent with cellulosic biopolymer, and $\mathrm{C}<\mathrm{O}$ for the core particles.

The weight of multi-spectroscopic evidence thus indicates that the summer (WO4) and spring (WO8) biomass particles do not represent the same type of biomass. Rather, the WO4 particles appear to include a soot component from high temperature combustion (motor vehicles, wildfires). The WO8 particles, whose carbon derives almost entirely from biomass, appear to have a major biopolymer component, such as cellulose and other bio-materials associated with soil and vegetative carbon. These findings are consistent with work by Puxbaum and colleagues, who have found by direct chemical analysis, significant amounts of cellulose, bacteria, and fungal spores in atmospheric particles [58, 59]. 


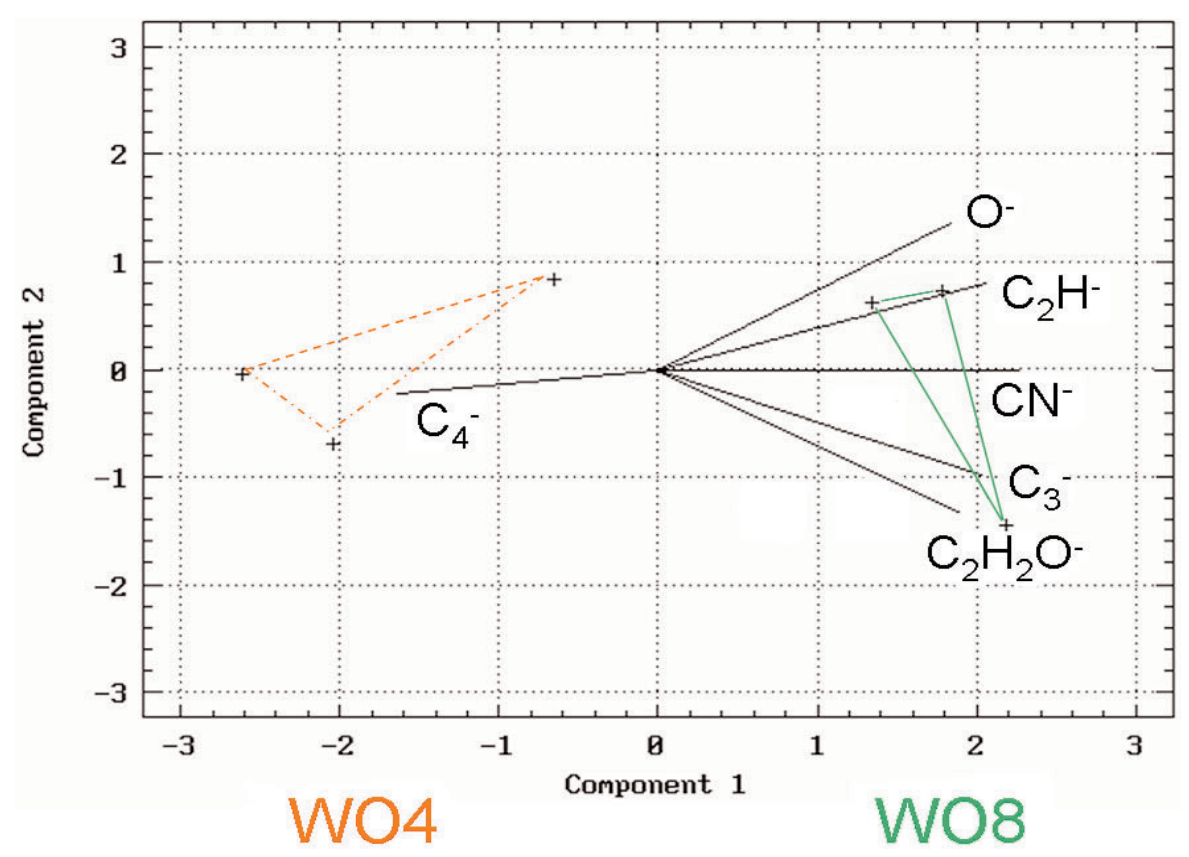

Fig. 22. PCA biplot of laser microprobe mass spectral data; compositional contrast between particles from the summer biomass peak (WO4, red: $\mathrm{C}_{n}^{-}$cluster ions favored) and the spring biomass peak (WO8, green: oxygenates favored) [55].

\subsection{Isotopic Speciation in Ancient Bones and Contemporary Particles}

The dating of ancient bones has been notably unreliable because of diagenesis and isotopic contamination that occur with millennia of environmental exposure. Molecular dating of individual amino acids in such bones has proven to be one of the most effective means to overcome this problem. Figure 23 shows dramatically how the apparent radiocarbon age of the Dent Mammoth changed from ca. $8000 \mathrm{BP}$ to ca. $11000 \mathrm{BP}$, as the dated chemical fraction was refined from the crude collagen fraction to the individual amino acids. The known radiocarbon age is given as $\approx 11,000 \mathrm{BP}$, based on association with Clovis culture artifacts, and biostratigraphy [60]. (Note that the "calibrated" or corrected calendar age, derived from the radiocarbon calibration curve [13], is roughly 1500 years older than the radiocarbon age for this time period.) The commonly dated organic fractions from bones (weak acid insoluble collagen [COLL] and gelatin $[\mathrm{GEL}]$ ) gave ages that were at odds with the archaeological evidence-suggesting recent humate contamination. When the diagenesis-resistant molecular components were isolated (individual amino acids and the collagen hydrolysates [XAD-HYD]), age concordance among the individual amino acids and with the archaeological evidence indicated reliability. Had contamination from bio-intrusive material having a different chemical (amino acid) pattern occurred, amino acid age heterogeneity would have been expected [60]. This work could not have been accomplished without the ability to date $80 \mu \mathrm{g}$ carbon fractions.

An historical footnote related to this work involves the question of the ancestors of the North American Clovis culture. Since the Clovis sites give the earliest unequivocal data on the "peopling" of the Americas, it has been of enormous interest to find a geochronological link to an earlier culture. The most popular belief that the Clovis progenitors had arrived over the "Bering Land Bridge" from Siberia has recently been put into doubt, however, with new ${ }^{14} \mathrm{C}$ evidence that one of the most likely pre-Clovis sites in northeastern Siberia is 4000 years younger than previously believed. Dating at $\approx 13000$ calendar years ago, it is doubtful that migration could have transpired quickly enough to give rise to the Clovis culture (13 600 to 12600 calendar years BP) in the North American Southwest [61]. 


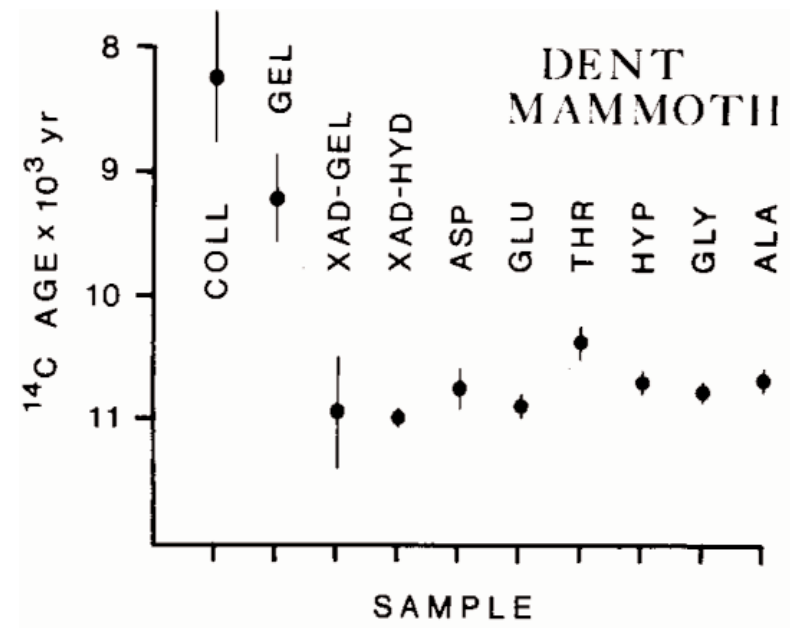

Fig. 23. "Molecular Dating" of individual amino acids in ancient bone. Radiocarbon ages of commonly dated (collagen, gelatin) fractions were 2000 to 3000 years too young as a result of environmental degradation; pure molecular fractions (amino acids) were self-consistent and in agreement with the Clovis culture age [60].

\subsubsection{Urban Dust (SRM 1649a): a Unique Isotopic-Molecular Reference Material}

SRM 1649a is NIST's most highly characterized natural matrix Standard Reference Material, and it is the only one for which there are certificate values for ${ }^{14} \mathrm{C}$ in individual chemical fractions and pure molecular species. The "carbon" portion of the Certificate of Analysis was developed through an extensive international interlaboratory comparison, involving eighteen teams of analytical experts from eleven institutions [62]. The particle-based SRM, which has been characterized for nearly 200 chemical species and properties, serves as an essential quality assurance material for a remarkably broad range of disciplines, from the monitoring of pesticides, PCBs, and particulate mutagenic activity to basic organic geochemistry to isotopic apportionment of carbonaceous particles. A dramatic illustration of the ${ }^{14} \mathrm{C}$ isotopic heterogeneity in this reference material is given in Fig. 24. The biomass carbon mass fractions are seen to range from about $2 \%$ (aliphatic extract) to $38 \%$ (total carbon). Thus, the aliphatic fraction derives essentially ( $\approx 98 \%)$ from fossil fuel emissions, and, on average, fossil sources account for some $60 \%$ of the carbon in these particles.

Note that the Certificate of Analysis [63] provides ${ }^{14} \mathrm{C}$ data expressed in the proper reference units as fraction of modern carbon $\left(f_{\mathrm{M}}\right)$. To emphasize the more meaningful fossil-biomass carbon source dichotomy, however, we have chosen to present the information here in terms of the fraction of biomass carbon. Conversion is based on the "post-bomb" enrichment of ${ }^{14} \mathrm{C}$ in the living biosphere, as shown in Fig. 11. Sampling for SRM 1649a took place in 1976-1977; the enrichment factor for biomass carbon at that time, indicated by the red arrow in the figure, was 1.35.

One of the most important outcomes of the SRM 1649a intercomparison exercise was the set of data obtained for "elemental carbon" (EC). EC (sometimes known as "black carbon") is routinely monitored in urban and rural aerosols, and it is of major concern because of its presumed impacts on health, visibility, and climate (radiation absorption). SRM 1649a potentially can serve as a key laboratory quality assurance reference material for EC measurement. Results of the largest intercomparison to date of $\mathrm{EC}$ in a uniform reference material, however, indicate a severe measurement problem: relative values for the reported data span a range of 7.5 , showing very significant method dependence. Three clusters of results for the mass fraction of EC (relative to total-C), reported as information values on the Certificate of Analysis, are $0.075,0.28$, and 0.46. (For the ${ }^{14} \mathrm{C}$ data in Fig. 24, cluster-1 EC has been labeled "soot" and cluster-3 EC, "char." ${ }^{14} \mathrm{C}$ was not determined in cluster-2 EC.) The fundamental problem is that EC is not a pure substance, so a unique "true value" for EC may not exist, in principle. ${ }^{16}$ Some interesting insights into the meaning of certain of the EC results follow, however, from the ${ }^{14} \mathrm{C}$ EC speciation data.

\footnotetext{
${ }^{16}$ Although a "true" (Certified) EC value may be beyond reach, compatibility of results from laboratories using the same method suggests the possibility of method-specific ("operational") EC Reference Values for this SRM.
} 


\section{Urban Particulate Reference Material (SRM 1649a) (prototypical isotopic-chemical aerosol reference/QA material)}

\begin{tabular}{lc}
\multicolumn{2}{c}{${ }^{14} \mathbf{C}$ SPECIATION } \\
CARBON & BIOMASS-C (\%) \\
total & 38 \\
polar & 32 \\
elemental & \\
"char" & 11 \\
"soot" & 4 \\
aromatic & 13 \\
aliphatic & 2 \\
Pyrene & 3 \\
Benzo(ghi)perylene & 6 \\
(U =6 [aromatic]; others $<1)$
\end{tabular}

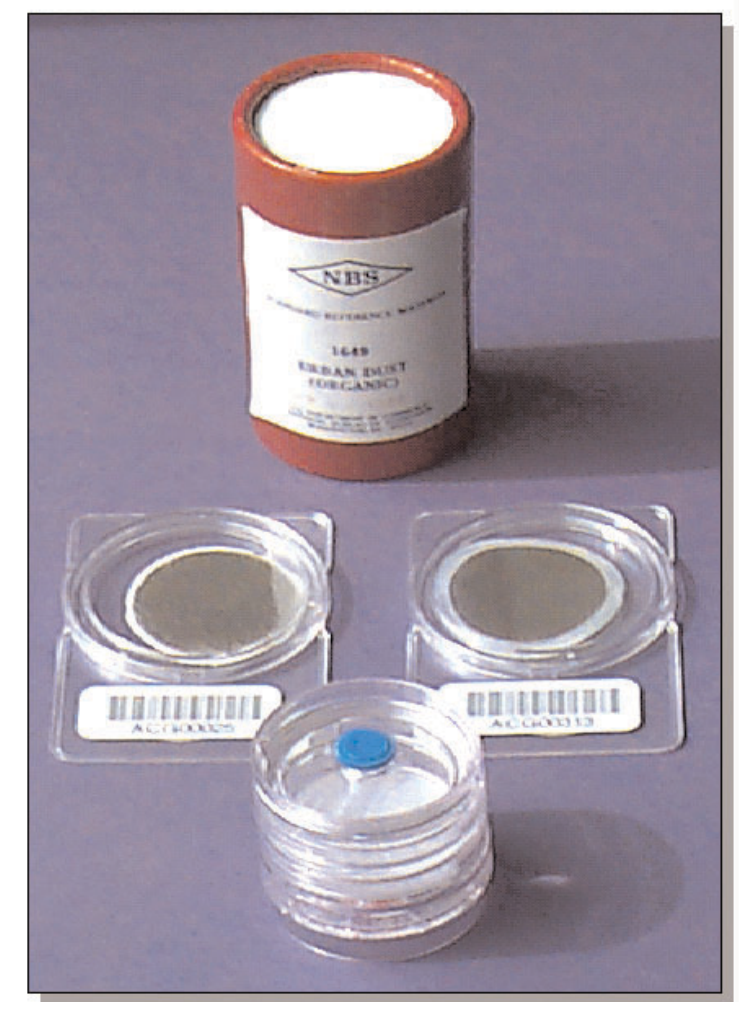

Fig. 24. NIST Standard Reference Material 1649a ("urban dust"). Photograph of the bulk reference material and derived "filter samples" for QA of atmospheric elemental carbon (EC). ${ }^{14} \mathrm{C}$ data listed indicate the mass fraction (\%) of biomass-C in the several chemical fractions $[29,62]$.

Isotopic consistency. Measurement of ${ }^{14} \mathrm{C}$ in multiple chemical fractions offers the possibility of two very interesting and important consistency tests: (1) assessment of isotopic-chemical consistency among chemically-related fractions, and (2) assessment of overall isotopic-mass balance. The first test is illustrated by comparison of the ${ }^{14} \mathrm{C}$ content of the $\mathrm{EC}$ fraction with that of the PAH fraction (on average). To the extent that both components originate from the same source, acetylenic free radicals that generate polyaromatic structures in the flaming stage of combustion, one would expect similar ${ }^{14} \mathrm{C}$ composition. Such is the case for ${ }^{14} \mathrm{C}$ in cluster-1 EC (labeled "soot" in Fig. 24), but not for cluster-3 EC (labeled "char"). The lack of isotopic consistency for cluster-3 EC is the stimulus for the different label, since this manifestation of EC necessarily reflects a different mix of fossil-biomass sources than the flaming stage EC, which derives primarily from fossil fuel carbon.
Regarding the second test, the ${ }^{14} \mathrm{C}$ data in Fig. 24 demonstrate that isotopic-mass balance cannot be achieved with the current isotopic-chemical data. Since the biomass carbon fraction on average (38\% mass fraction) exceeds that of all other measured fractions, there must be a significant missing biomass carbon component. This matter is addressed in [62], where it is suggested that unmeasured biopolymers may account for more than $45 \%$ of the residual (non-extractable, non-EC) carbon mass. Cellulose is one excellent candidate [58].

GC/AMS. Finally, the "molecular dating" of individual PAH in SRM 1649a epitomizes one of the latest advances in micromolar ${ }^{14} \mathrm{C}$ measurement science: the capability to link chromatographic isolation of pure chemical compounds to AMS determination of ${ }^{14} \mathrm{C}^{/ 12} \mathrm{C}$. Results of applying off-line GC/AMS to six PAHs recovered from the aromatic fraction of SRM 1649a are 

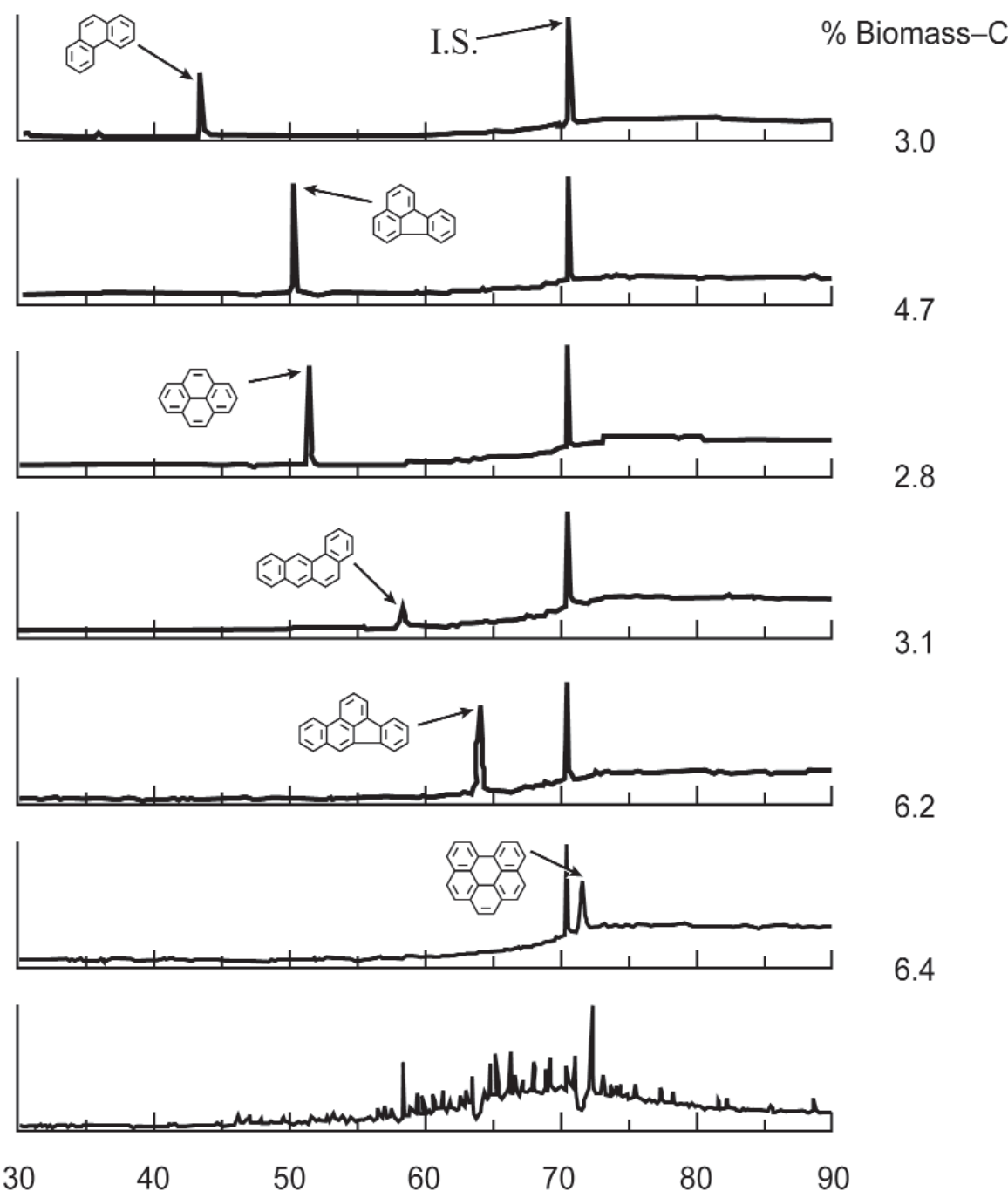

Fig. 25. Gas chromatography/accelerator mass spectrometry (GC/AMS): AMS following automated prep-scale capillary GC yields "dates" (equivalent biomass carbon mass fractions) for micromolar amounts of individual polycyclic aromatic hydrocarbons [63-65]. (Results shown for NIST SRM 1649a; "I.S." denotes an internal standard; abscissa indicates retention time (min).)

shown in Fig. 25. The critical first step was the sequential isolation of tens of micrograms of the six PAHs in separate traps by automated preparative scale capillary gas chromatography [66]. The individually trapped PAHs were then oxidized and converted to AMS targets. These results represent the first such data ever available for an atmospheric particulate SRM, and although such compounds are only trace constituents of atmospheric particles $(\approx 10 \mu \mathrm{g} / \mathrm{g})$, they are of great consequence due to their mutagenic and carcinogenic properties. In this case, as shown in Fig. 25, radiocarbon dating of the individual PAHs revealed these congeners to be isotopically heterogeneous, and demonstrated a basic flaw in the conventional wisdom that the heavier PAHs, in particular, are more likely to be produced strictly from fossil fuel combustion sources.

On-line GC/AMS is nearly upon us. The linkage of gas (or liquid) chromatographic separation, and direct injection of microgram amounts of pure compounds into the ion source of an accelerator mass spectrometer, is under active investigation in several AMS laboratories; and it promises a new dimension in the practice of radiocarbon dating at the molecular level that may have an impact on archaeology and isotopic biogeochemistry comparable to that of GC/MS on analytical, physical, organic, and biochemistry [67]. 


\section{Epilogue}

Libby's discovery, and the remarkable developments that followed, arose from a scientific question (freely translated): "What will become of the cosmic ray neutrons?" It is noteworthy that an "academic son" of this Nobel Laureate also posed a scientific question to himself. F. Sherwood Rowland's question also led to an unexpected discovery having major practical import for mankind: the possible destruction of the stratospheric ozone layer. Rowland's query, also culminating in a Nobel Prize (1995), was "I began to wonder what was going to happen to this man-made compound [trichlorofluoromethane] newly introduced into the atmosphere" [68].

May this historical journey into scientific discovery, as an outgrowth of seemingly simple scientific curiosity, and the consequent unanticipated scientific-metrological revolutions, encourage students to examine the original historical literature documenting such discoveries, and to realize that profound unforeseen developments may be in store for a presumably "mature" scientific discipline.

\section{Acknowledgment}

This article represents an adaptation and extension of a recent publication in the Czechoslovak Journal of Physics: "The Remarkable Metrological History of ${ }^{14} \mathrm{C}$ Dating: from ancient Egyptian artifacts to particles of soot and grains of pollen" [Czech. J. Phys. 53, (Suppl. A) A137-A160 (2003)]. Permission of the Institute of Physics, Academy of Sciences of the Czech Republic is gratefully acknowledged. Thanks go also to Cynthia Zeissler and Ed Mai for assistance in final preparation of the figures for publication.

Figures are adapted, with permission, from the following sources. Fig. 1: photo by Fabian Bachrach (AEC-54-5123-DOE) from page 1 of: de Messières, N.: "Libby and the interdisciplinary aspect of radiocarbon dating." Radiocarbon 43 (2001) 1-5; copyright 2001 Arizona Board of Regents on behalf of the University of Arizona. Fig. 3, from Radiocarbon Dating [jacket cover] (Eds. R. Berger and H. Suess) Univ. California Press, Berkeley, 1979]. Fig. 4, from Fig. 1 of: Libby, Willard F., Radiocarbon Dating, Univ. Chicago Press, Chicago, copyright 1952 (1st edition). Cover and Fig. 5 (plot), from Fig. 1 (p. 110) in: Olsson, I.U., Ed. Radiocarbon Variations and Absolute Chronology (12th Nobel Symposium), Almqvist \& Wiksell, Stockholm, 1970; copyright, the Nobel Foundation. Fig. 5 (photo), courtesy of Douglas J. Donahue, University of Arizona. Fig. 6a (top), reprinted with permission from Fig. 5a in: Eddy, J.: "The Maunder Minimum," Science 192 (1976) 1189-1202; copyright 1976 American Association for the Advancement of Science. Fig. 6b (bottom), from the "climate" figure (p. 615, last segment only, labeled "Past 1000 years") in: Mathews, S.: "What's happening to our climate," National Geographic 150 (1976) 176-615; copyright 1976 the National Geographic Society. Fig. 7 and Fig. 8, from: Toggweiler, J.R., Dixon, K. and Bryan, K.: "Simulations of Radiocarbon in a Coarse-Resolution World Ocean Model, 2. Distributions of bomb-produced ${ }^{14}$ C," J Geophys Res 94 [C6] (1989) 8243-8264 (figures 1 and 17, respectively); copyright 1989 American Geophysical Union. Figures 9 and 10 are adapted from Currie, L.A., et al., "Authentication and Dating of Biomass Components of Industrial Materials: Links to Sustainable Technology," Nuclear Instruments and Methods in Physics Research B172 pp 281-287, copyright (2000), with permission from Elsevier Science. Fig. 12: photos are courtesy of Robert K. Stevens. Fig. 13, from Fig. 1 in: Wölfli, W.: “Advances in accelerator mass spectrometry," Nuclear Instruments and Methods in Physics Research B29 [numbers 1, 2] pp 1-13, copyright (1987), with permission from Elsevier Science. Fig. 14, from Fig. 16.2 in: Taylor, R.E., Long, A., and Kra, R., Eds.: Radiocarbon after Four Decades: an Interdisciplinary Perspective; copyright Springer-Verlag, New York, 1992. Fig. 15c inset (negative image) and 15d (microphotograph), from: British Broadcasting Corporation Documentary, "Shreds of Evidence" (Timewatch Series), copyright 1988. Fig. 15b, courtesy of Douglas J. Donahue, University of Arizona. Figures 15a (reprint cover), 16, and 17, from Damon, P., et al.: "Radiocarbon dating of the Shroud of Turin," Nature 337 (1989) 611-615; copyright Macmillan Magazines Ltd, 1989. Fig. 18, from: (a) Currie, L.A., et al.: "The pursuit of isotopic and molecular fire tracers in the polar atmosphere and cryosphere," Radiocarbon 40 (1998) 381-390, 416f; copyright 1998 Arizona Board of Regents on behalf of the University of Arizona; and (b) Mark Twickler, Univ. New Hampshire. Fig. 19 (center, backtrajectories), from Dibb, J.E., et al., "Biomass burning signatures in the atmosphere and snow at Summit, Greenland: an event on 5 August 1994," Atmospheric Environment 30 pp 553-561 copyright (1996), with permission from Elsevier Science. Figures 19, 20 adapted from Currie, L.A., et al., "The pursuit of isotopic and molecular fire tracers in the polar atmos- 
phere and cryosphere," Radiocarbon 40 (1998) 381390, 416f; copyright 1998 Arizona Board of Regents on behalf of the University of Arizona. Fig. 23, from Fig. 1 in: Stafford, T.W., Jr., Hare, P.E., Currie, L.A., Jull, A.J.T., and Donahue, D.: "Accuracy of North American Human Skeleton Ages", Quarternary Research, 34, pp 111-120, copyright (1990), with permission from Elsevier Science. Fig. 24, adapted from Fig. 4 in Currie, L.A., "Evolution and Multidisciplinary Frontiers of ${ }^{14} \mathrm{C}$ Aerosol Science," Radiocarbon 42 (2000) 115-126, copyright 2000 Arizona Board of Regents on behalf of the University of Arizona. Fig. 25, from Fig. 2 in: Currie, L.A., Klouda, G.A., Benner, Jr., B.A., Garrity, K., and Eglinton, T.I., "Isotopic and Molecular Fractionation in Combustion; Three Routes to Molecular Marker Validation, including Direct Molecular 'Dating' (GC/AMS)," Atm. Environ. 33 (1999) 2789-2806; published by Elsevier Science Ltd.

\section{References}

[1] W. F. Libby, Nuclear dating: an historical perspective, Nuclear and Chemical Dating Techniques: Interpreting the Environmental Record, L. A. Currie, ed., American Chemical Society Symposium Series No. 176 (1982) Chap. 1.

[2] Willard F. Libby, Radiocarbon Dating, Univ. Chicago Press, Chicago (1952).

[3] N. de Messières, Libby and the interdisciplinary aspect of radiocarbon dating. Radiocarbon 43, 1-5 (2001).

[4] W. F. Libby, Radiocarbon dating (Nobel Lecture), Science 133, 621-629 (1961).

[5] W. F. Libby, Atmospheric Helium-3 and Radiocarbon from cosmic radiation, Phys. Rev. 69, 671-672 (1946).

[5a] H. Godwin, Half-life of radiocarbon, Nature 195, 984 (1962).

[6] E. C. Anderson, W. F. Libby, S. Weinhouse, A. F. Reid, A. D. Kirshenbaum, and A. V. Grosse, Radiocarbon from cosmic radiation, Science 105, 576 (1947). (See also C. MacKay, M. Pandow, and R. Wolfgang, On the chemistry of natural radiocarbon, J. Geophys. Res. 68, 3929-3931 (1963), for an account of ${ }^{14} \mathrm{CO}$ as the precursor of cosmogenic ${ }^{14} \mathrm{CO}_{2}$.)

[7] E. C. Anderson and W. F. Libby, World-wide distribution of natural radiocarbon, Phys. Rev. 81, 64-69 (1951).

[8] J. R. Arnold and W. F. Libby, Age determination by radiocarbon content: checks with samples of known age, Science 110, 678-680 (1949)

[9] I. Karlén, I. Olsson, P. Kallberg, and S. Killici, Absolute determination of the activity of two ${ }^{14} \mathrm{C}$ dating standards, Ark. Geofys. 4, 465 (1964). (See also Ref. [12], p. 17, The use of oxalic acid as a [radiocarbon dating] standard.)

[10] NIST Standard Reference Materials website: http://nist.gov/srm.

[11] K. Rozanski, W. Stichler, R. Gonfiantini, E.M. Scott, R. Beukens, B. Kromer, and J. van der Plicht, The IAEA intercomparison exercise 1990, Radiocarbon 34, 506-519 (1992).
[12] I. U., Olsson, ed., Radiocarbon Variations and Absolute Chronology (12th Nobel Symposium), Almqvist \& Wiksell, Stockholm (1970).

[13] M. Stuiver and R. Kra, eds., Calibration Issue, Radiocarbon 28, 2B (1986); Stuiver, M., Long, A., Kra, R., eds., Calibration 1993, Radiocarbon 35 (1), 191-199 (1993).

[14] M. Geyh and C. Schlüchter, Calibration of the ${ }^{14} \mathrm{C}$ time scale beyond 22,000 BP, Radiocarbon 40, 475-482 (1998).

[15] J. Eddy, The Maunder Minimum, Science 192, 1189-1202 (1976). (See Fig. 3)

[16] S. Mathews, What's happening to our climate, National Geographic 150, 176-615 (1976). (See especially pp. 586, $614 \mathrm{f})$.

[17] J. Lopes, R. Pinto, M. Almendra, and J. Machado, Variation of ${ }^{14} \mathrm{C}$ activity in Portuguese wines from 1940 to 1974, Proc. Int. Conf. on Low-Radioactivity Measurements and Applications: The High Tatras, Czechoslovakia, 6-10 October 1975, P. Povinec and S. Usacev, eds., Comenius Univ., Bratislava (1977) pp. $265-268$

[18] W. F. Cain, ${ }^{14} \mathrm{C}$ in Modern American Trees, in Radiocarbon Dating, R. Berger and H. Suess, eds., Univ. California Press, Berkeley (1979) pp. 495-510.

[19] J. R. Toggweiler, K. Dixon, and K. Bryan, Simulations of Radiocarbon in a Coarse-Resolution World Ocean Model, 2. Distributions of bomb-produced ${ }^{14} \mathrm{C}$, J. Geophys. Res. (C6) 94, 8243-8264 (1989). [See also: I. Levin and V. Hesshaimer, Radiocarbon-a unique tracer of global carbon cycle dynamics, Radiocarbon 42, 69-80 (2000).]

[20] R. E. Taylor, A. Long, and R. Kra, eds., Radiocarbon After Four Decades: An Interdisciplinary Perspective, Springer-Verlag, New York (1992).

[21] M. Stuiver and G. Östlund, GEOSECS Atlantic Radiocarbon, Radiocarbon 22, 1-24 (1980).

[22] J. Sarmiento, and N. Gruber, Sinks for anthropogenic carbon, Physics Today 55, 30-36 (8) (2002). [See also: R. Nydal, Radiocarbon in the Ocean, Radiocarbon 42, 81-98 (2000).]

[23] A. P. McNichol, R. J. Schneider, K. F. von Reden, A. R. Gagnon, K. L. Elder, NOSAMS, R. M. Key and P. D. Quay, Ten years after: The WOCE AMS radiocarbon program, Nucl. Instrum. Meth. Phys. Res. B172, 479-484 (2000).

[24] E. M. Wild, K. A. Arlamovsky, R. Golser, W. Kutschera, A. Priller, S. Puchegger, W. Rom, P. Steier, and W. Vycudilik, ${ }^{14} \mathrm{C}$ dating with the bomb peak: an application to forensic medicine, Nucl. Instrum. Meth. Phys. Res. B172, 944-950 (2000).

[25] L. Currie, D. Klinedinst, R. Burch, N. Feltham, and R. Dorsch, Authentication and Dating of Biomass Components of Industrial Materials: Links to Sustainable Technology, Nucl. Instrum. Meth. Phys. Res. B172, 281-287 (2000).

[26] G. Clayton, J. Arnold, and F. Patty, Determination of Sources of Particulate Atmospheric Carbon, Science 122, 751-753(1955).

[27] J. P. Lodge, G. S. Bien, and H. E. Suess, The Carbon-14 Content of Urban Airborne Particulate Matter, Int. J. Air Pollut. 2, 309 (1960).

[28] T. H. Maugh, Air pollution: where do hydrocarbons come from? Science 189, 277 (1975).

[29] L. A. Currie, Evolution and Multidisciplinary Frontiers of ${ }^{14} \mathrm{C}$ Aerosol Science, Radiocarbon 42, 115-126 (2000). 
[30] R. K. Stevens, C. W. Lewis, T. G. Dzubay, R. E. Baumgardner, R. B. Zweidinger, V. R. Highsmith, L. T. Cupitt, J. Lewtas, L. D. Claxton, L. A. Currie, G. A. Klouda, and B. Zak, Mutagenic Atmospheric Aerosol Sources Apportioned by Receptor Modeling, ASTM Monograph STP 1052, Monitoring Methods for Toxics in the Atmosphere, W. L. Zielinski, Jr. and W. D. Dorko, eds., Amer. Soc. Testing Mtls., Philadephia (1990) pp. 187-196.

[31] D. B. Klinedinst, and L. A. Currie, Direct Quantification of PM2.5 Fossil and Biomass Carbon within the Northern Front Range Air Quality Study's Domain, Environ. Sci. Technol. 33, 4146-4154 (1999).

[32] G. A. Klouda, C. W. Lewis, D. C. Stiles, J. L. Marolf, W. D. Ellenson, and W. A. Lonneman, Biogenic contributions to atmospheric volatile organic compounds in Azusa, California, J. Geophys. Res. 107 (D8) 10.1029/2001JD000758 (2002).

[33] T. Kuc and M. Zimnoch, Changes of the $\mathrm{CO}_{2}$ sources and sinks in a polluted urban area (Southern Poland) over the last decade, derived from the carbon isotope composition, Radiocarbon 40, 417-423 (1998).

[34] R. A. Muller, Radioisotope dating with a cyclotron, Science 196, 489-494 (1977).

[35] D. Nelson, R. Korteling, and W. Stott, Carbon-14: Direct detection at natural concentrations, Science 198, 507-508 (1977).

[36] C. L. Bennett, R. P. Beukens, M. R. Clover, H. E. Gove, R. B. Liebert, A. E. Litherland, K. H. Purser, and W. E. Sondheim, Radiocarbon dating using electrostatic accelerators: negative ions provide the key, Science 198, 508-510 (1977).

[37] W. Wölfli, Advances in accelerator mass spectrometry, Nucl. Instrum. Meth. Phys. Res. B29, 1-13 (1987).

[38] P. Damon, D. J. Donahue, B. H. Gore, A. L. Hatheway, A. J. T. Jull, T. W. Linick, P. J. Sercel, L. J. Toolin, C. R. Bronk, E. T. Hall, R. E. M. Hedges, R. Housley, I. A. Law, C. Perry, G. Bonani, S. Trumbore, W. Wölfli, J. C. Ambers, S. G. E. Bowman, M. N. Leese, and M. S. Tite, Radiocarbon dating of the Shroud of Turin, Nature 337, 611-615 (1989). (See also the website: www.shroud.com/papers.htm for this article (.../nature.htm) and others contained in a large on-line collection of scientific articles treating various aspects of Shroud research.)

[39] British Broadcasting Corporation: Documentary, Shreds of Evidence, Timewatch series (1988).

[40] H. Gove, Relic, Icon, or Hoax? Carbon Dating the Turin Shroud, Institute of Physics Publishing, Bristol and Philadelphia (1996).

[41] I. Wilson, An appraisal of the mistakes made regarding the Shroud samples taken in 1988, Proc. 3rd Intern. Conf. on the Shroud of Turin. Turin, June 1998. (www.shroud.com/wilson.htm).

[42] Articles examining non-contemporaneous organic contamination of textiles: 1) H. Gove, S. Mattingly, A. David, and L. Garza-Valdes, A problematic source of organic contamination of linen, Nucl. Instrum. Meth. Phys. Res. B123, 504-507 (1997) ; 2) A. Jull, D. Donahue, and P. Damon, Factors that affect the apparent radiocarbon age of textiles, Archaeological Chemistry, M. Orna, ed., ACS symposium series 625, American Chemical Society, Washington DC (1996) Chap. 19, pp. 248-253.

[43] L. A. Currie, J. D. Kessler, J. V. Marolf, A. P. McNichol, D. R. Stuart, J. C. Donoghue, D. J. Donahue, G .S. Burr, and D. Biddulph, Low-level (submicromole) environmental ${ }^{14} \mathrm{C}$ metrology, Nucl. Instrum. Meth. Phys. Res. B172, 440-448 (2000).

[44] D. B. Klinedinst, and L. A. Currie, Radiocarbon blank correction: Methodologies and limitations in a major urban study of carbonaceous aerosols, Nucl. Instrum. Meth. Phys. Res. B172, $545-550$ (2000).

[45] L. A. Currie, E. M. Eijgenhuijsen, and G. A. Klouda, On the validity of the Poisson Hypothesis for low-level counting; investigation of the distributional characteristics of background radiation with the NIST Individual Pulse Counting System, Radiocarbon 40, 113-127 (1998).

[46] L. A. Currie, Some case studies of skewed (and other abnormal) data distributions arising in low-level environmental research, Fresenius J. Anal. Chem. 370, 705-718 (2001).

[47] A. Danin, and U. Baruch, Floristic indicators for the origin of the Shroud of Turin, Proc. 3rd Intern. Conf. on the Shroud of Turin. Turin, June 1998. (www.shroud.com/pdfs/daninx.pdf).

[48] A. Long, O. Davis, and J. de Lanois, Separation and ${ }^{14} \mathrm{C}$ dating of pure pollen from lake sediments: nanofossil AMS dating," Radiocarbon 34, 557-560 (1992).

[49] L. A. Currie, J. E. Dibb, G. A. Klouda, B. A. Benner, Jr., J. M. Conny, S. R. Biegalski, D. B. Klinedinst, D. R. Cahoon, and N. C. Hsu, The pursuit of isotopic and molecular fire tracers in the polar atmosphere and cryosphere, Radiocarbon 40, 381390, 416f (1998). [See also: N.C. Hsu, J. R. Herman, P .K. Bhartia, C. J. Seftor, O. Torres, A. M. Thompson, J. F. Gleason, T .F. Eck, and B. N. Holben, Detection of biomass burning smoke from TOMS measurements, Geophys. Res. Lett. 23, 745-748 (1996).

[50] R. Weissenbök, L. A. Currie, C. Grollert, W. Kutschera, A. Priller, H. Puxbaum, W. Rom, P. Steier, and J. Marolf, Accelerator Mass Spectrometry Analysis of Non-soluble Carbon in Aerosol Particles from High Alpine Snow (Mt. Sonnblick, Austria), Radiocarbon 42, 285-294 (2000).

[51] CARBOSOL: Present and retrospective state of organic vs inorganic aerosol over Europe: implications for climate, European Union; M. Legrand, coordinator, (2001-).

[52] J. E. Dibb, R. W. Talbot, S. I. Whitlow, M. C. Shipham, J. Winterle, J. McConnell, and R. Bales, Biomass burning signatures in the atmosphere and snow at Summit, Greenland: an event on 5 August 1994, Atmospheric Environment 30, 553561 (1996).

[53] J. F. Slater, L. A. Currie, J. E. Dibb, and B. A. Benner, Jr., Distinguishing the relative contribution of fossil-fuel and biomass combustion aerosols deposited at Summit, Greenland, through isotopic and molecular characterization of insoluble carbon, Atmospheric Environment 36, 4463-4477 (2002).

[54] J. E. Dibb, convenor, American Geophysical Union Special Session: Relationships Between the Composition of the Atmosphere and Snow, AGU Fall Meeting (San Francisco, December 1998).

[55] L. A. Currie, J. D. Kessler, R. A. Fletcher, and J. E. Dibb, Long-range transport of biomass aerosol to Greenland: multispectroscopic investigation of particles deposited in the snow, $\mathrm{J}$ Radioanal. Nucl. Chem. 263 (2005) in press.

[56] J. D. Kessler, L. A. Currie, E. S. Windsor, and D. E. Newbury, Seasonal record of total particulate matter embedded in Greenland surface snow, Microsc. Microanal. 7, 478-479 (2001).

[57] R. Fletcher, R. Dobbins, and H.-C. Chang, Mass Spectrometry of particles Formed in a Deuterated Ethene Diffusion Flame, Anal. Chem. 70, No. 13, 2745-2749 (1998). 
[58] H. Puxbaum, and M. Tenze-Kunit, Size distribution and seasonal variation of atmospheric cellulose, Atmospheric Environ. 37, 3693-3699 (2003).

[59] H. Bauer, A. Kasper-Giebl, M. Löflund, H. Giebl, R. Hintzenberger, F. Zibuschka, and H. Puxbaum, The contribution of bacteria and fungal spores to the organic carbon content of cloud water, precipitation and aerosols, Atmospheric Research 64, 109-119 (2002).

[60] T. W. Stafford, Jr., P. E. Hare, L. A. Currie, A. J. T. Jull, and D. Donahue, Accuracy of North American Human Skeleton Ages, Quarternary Res. 34, 111-120 (1990).

[61] T. Goebel, M. R. Waters, and M. Dikova, The archaeology of Ushki Lake, Kamchatka, and the Pleistocene peopling of the Americas, Science 301, 501-505 (2003).

[62] L. A. Currie, B. A. Benner, Jr., H. Cachier, R. Cary, J. C. Chow, E. R. M. Druffel, T. I. Eglinton, O. Gustafsson, P. C. Hartmann, J. I. Hedges, J. D. Kessler, T. W. Kirchstetter, D. B. Klinedinst, G. A. Klouda, J. V. Marolf, C. A. Masiello, T. Novakov, A. Pearson, K. M. Prentice, H. Puxbaum, J. G. Quinn, C. M. Reddy, H. Schmid, J. F. Slater, J. Watson, and S. A. Wise, A Critical Evaluation of Interlaboratory Data on Total, Elemental, and Isotopic Carbon in the Carbonaceous Particle Reference Material, NIST SRM 1649a, J. Res. Natl. Inst. Stand. Technol. 107, 279-298 (2002).

[63] NIST SRM 1649a (Urban Dust) Certificate of Analysis, Jan. 2001 (http://nist.gov/srm).

[64] C. M. Reddy, A. Pearson, L. Xu, A. P. McNichol, B. A. Benner, Jr., S. A. Wise, G. A. Klouda, L. A. Currie, and T. I. Eglinton, Radiocarbon as a tool to apportion the sources of polycyclic aromatic hydrocarbons and black carbon in environmental samples, Environ. Sci. Technol. 36, 1774-1782 (2002).

[65] L. A. Currie, G. A. Klouda, B. A. Benner, Jr., K. Garrity, and T. I. Eglinton, Isotopic and Molecular Fractionation in Combustion; Three Routes to Molecular Marker Validation, including Direct Molecular "Dating" (GC/AMS), Atm. Environ. 33, 2789-2806 (1999).

[66] T. I. Eglinton, L. I. Aluwihare, J. E. Bauer, E. R. M. Druffel, and A. P. McNichol, Gas chromatographic isolation of individual compounds from complex matrices for radiocarbon dating, Anal. Chem. 68, 904-912 (1996).

[67] B. Hughey, P. L. Skipper, R. E. Klinkowstein, R. E. Sheffer, J. S. Wishnok, and S. R. Tannenbaum, Low-energy biomedical GC-AMS system for ${ }^{14} \mathrm{C}$ and ${ }^{3} \mathrm{H}$ detection, Nucl. Instrum. Meth. Phys. Res. B172, 40-46 (2000).

[68] F. S. Rowland, Atmospheric Chemistry; Causes and Effects, Marine Technol. Soc. J. 25, 12-18 (1991).

\footnotetext{
About the author: Dr. L.A. Currie is an NIST Fellow Emeritus in the Chemical Science and Technology Laboratory. The ideas behind this article were first conceived about 15 years ago in connection with lectures at NIH and the University of Maryland, and as an outgrowth of the author's research on environmental radiocarbon while leader of the Atmospheric Chemistry Group at NIST. The concept and scope of the article were crystallized in connection with luncheon talks at the Measurement Science Conference (1995) and the Radiochemical Measurement Conference
}

(2001), an invited NIST Sigma Xi lecture (1998), and a plenary lecture at the Fourteenth Radiochemical Conference (2002). At the Conference in 2002, Dr. Currie was presented the I.M. Marci medal, the highest award of the Czech Spectroscopic Society of the Czech Academy of Sciences. The National Institute of Standards and Technology is an agency of the Technology Administration, U.S. Department of Commerce. 